\title{
University teachers' perceptions of appropriate emotion display and high-quality teacher-student relationship: Similarities and differences across cultural-educational contexts
}

\author{
Gerda Hagenauer $^{\text {a1 }}$, Michaela Gläser-Zikuda ${ }^{\mathrm{b}}$, \& Simone E. Volet ${ }^{\mathrm{c}}$ \\ ${ }^{\mathrm{a} U n i v e r s i t y ~ o f ~ B e r n, ~ S w i t z e r l a n d ~}$ \\ ${ }^{\mathrm{b}}$ University of Erlangen-Nuremberg, Germany \\ ${ }^{\mathrm{c}}$ Murdoch University, Australia
}

Article received 27 January / revised 8 April / accepted 27 April / available online 12 May

\begin{abstract}
Research on teachers' emotion display and the quality of the teacher-student relationship in higher education is increasingly significant in the context of rapidly developing internationalization in higher education, with scholars (and students) moving across countries for research and teaching. However, there is little theoretically grounded empirical research in this area, and the different research strands remain relatively unconnected. The present study aimed to address this gap. Psychological, educational and cross-cultural theories were brought together to investigate the interplay of emotion display and the quality of the teacher-student relationship from a teachers' perspective and across "cultural-educational" contexts. Given that social interaction, and the mores and norms associated with emotion display are often culturally underpinned, this study explored how university teachers in two so-called "individualistic" countries with different educational systems displayed positive and negative emotions in their teaching and what they perceived as an ideal teacher-student relationship. Australian $(N=15)$ and German $(N=9)$ university teachers in teacher education were interviewed. The study revealed that while both groups viewed the open expression of positive emotions as integral to teaching, and negative emotions to be controlled based on their understanding of professionalism, significant group differences were also found. While the Australian teacher educators reported higher and more intense expression of positive emotions, their German counterparts reported more open anger display. Subtle yet noteworthy differences in the TSR quality between the two groups of teachers emerged. The findings of this study have implications for research and practice in international higher education.
\end{abstract}

Keywords: teacher emotions, emotion display, higher education, teacher-student relationship, cross-cultural comparison, internationalization of higher education

\footnotetext{
1 Corresponding author: Gerda Hagenauer; University of Bern, Institute of Educational Science, Fabrikstrasse 8, 3012 Bern, Switzerland; email: gerda.hagenauer@edu.unibe.ch Doi: http://dx.doi.org/10.14786/flr.v4i3.236
} 


\section{Introduction}

Emotions in teaching have received increased attention in educational research in the school context (Newberry, Gallant, \& Riley, 2013; Schutz \& Zembylas, 2011, Schutz, 2014). Teachers' experience of emotions and the communication of these emotions are expected to have a significant impact on the quality of their teaching practice and the socio-emotional climate in the classroom (Jennings \& Greenberg, 2009). While the literature on teacher emotions at school steadily increases, affective factors in teaching-learningprocesses remain largely neglected in the higher education (HE) literature (Beard, Clegg, \& Smith, 2004; Quinlan, 2016), in particular teacher emotions (Moore \& Kuol, 2007). However, recent empirical research has shown that teaching is also experienced emotionally in HE (Hagenauer \& Volet, 2014a; Postareff \& Lindblom-Ylänne, 2011), and is related to quality indicators of teaching, e.g. student-centered teaching (Trigwell, 2012), that affect students' learning (e.g., students' engagement; Zhang \& Zhang, 2013). Besides emotional aspects, the teacher-student relationship (= TSR) in HE is also a highly neglected field of research, in particular from a HE teachers' perspective (Hagenauer \& Volet, 2014c; Walker \& Gleaves, 2016). Some research has shown that emotions and relationships are strongly intertwined (e.g. Parkinson, Fischer, \& Manstead, 2005): If someone seeks to understand people's emotions in interactions, the quality of the relationship has to be considered as it contributes to the quality of the emotion evoked. In turn, the way emotions are communicated (= emotion display) contributes to the development of relationships (Boiger \& Mesquita, 2012). Thus, research that combines the two research strands - emotions / emotion display and the TSR - is warranted in order to better understand HE teacher-student interactions that form the basis of quality teaching and learning processes.

The research presented here follows an earlier study on Australian university teachers' emotions and emotion display (Hagenauer \& Volet, 2014a, b). The present research aimed to increase understanding in this area through a cross-cultural perspective, employing interview accounts of Australian and German HE teachers, and by bringing in the aspect of the TSR. Based on psychological research on cross-cultural differences in emotions combined with a social-psychological lens on emotions (Parkinson, Fischer, \& Manstead, 2005), we examined whether display modes of emotions differ between teachers in an Australian and German HE context, if differences in the quality of the TSR can be found between countries and how emotion display and the TSR are linked. Perceived differences in relationship quality may signal the presence of differences in display modes. The focus is on a particular group of teachers in HE, namely teacher educators, who fulfill a special function as they do not only teach content in their respective subject, but are also expected to model teaching behaviour to their students (Lunenberg, Korthagen, \& Swennen, 2007). Thus, the way university teacher educators relate to their students and how they display their emotions, does not only affect the teaching-learning-environment but also serves as a model for future school-teaching practices of pre-service teacher students.

The present study is innovative in three aspects: Firstly, in a field of research with scarce empirical evidence so far, it brings together in one study psychological and educational theoretical strands of research, which have traditionally been researched separately, namely research on teacher emotions, emotion display and the TSR in HE. The cross-cultural perspective adds another dimension, which is important to explore in the context of the internationalization of HE. Secondly, it adopts the concept of "cultural-educational context" (Volet, 2001), and thus moves beyond the frequently made cultural comparisons between collectivistic and individualistic countries. Thirdly, it uses a qualitative approach to investigate differences across cultural-education contexts. This enables an in-depth exploration of cultural-educational practices, which differs methodologically from the typically quantitative driven approaches used in cross-cultural emotion research (e.g. Safdar et al., 2009).

\subsection{Emotion and emotion display in higher education}

From an appraisal theoretical perspective (Ellsworth \& Scherer, 2003) it is assumed that emotions arise from the cognitive evaluation of a situation (e.g., a teacher judges the learning behaviour of a particular 
student). As evaluations of situations vary across people, the same situation can trigger different emotions in different people. According to this approach, emotions only develop if a situation is of relevance for people (= primary appraisal, Lazarus, 1999); otherwise people remain emotionally "untouched". Further appraisal cognitions, e.g. in terms of controllability or goal attainment, determine the quality of the respective emotion. Appraisals also influence whether people decide to suppress or to show the particular emotion.

The ability to display emotions appropriately is a competence that can be linked to teachers' overall emotion regulation competence (Gross, 2002). According to Gross (2010, p. 497) emotion regulation "refers to how we try to influence which emotions we have, when we have them, and how we experience and express these emotions." Emotion expression or emotion display are terms that describe the same phenomenon of how emotions are communicated, which is a constituent part of emotion regulation besides the internal regulation of emotion (e.g. down-regulating the intensity and duration of anger).

The (appropriate) expression of emotions in HE is discussed in various ways in the literature. In an overview, Gates (2000) identified studies in which authors have argued that a neutral teaching and learning environment may be best for students' learning in HE classrooms, which suggests emotion suppression. However, the majority of literature advocates for authenticity, which allows for teachers' emotion display in a controlled manner (e.g. Cranton \& Carusetta, 2004). An authentic display of emotions fulfills a relevant function in establishing genuine and caring relationships with students (Yuu, 2010; see also Fischer \& Manstead, 2010 discussing the social functions of emotions in general), and is also significant for maintaining teachers' health (Zhang \& Zhu, 2008). Research also suggests that emotion suppression can have adverse cognitive implications (Gross, 2010), which in turn may also impact teaching quality while cognitive resources and attention are focused on the process of emotion suppression.

The research strand on "emotional labour" discusses the requirement to mask emotions on the job (Hochschild, 1983). Employees aiming at successful fulfillment of work tasks are expected to follow particular occupational emotion display rules, which usually means masking (overly intense) negative feelings and acting in an emotionally positive manner. If students in HE are regarded as customers, this also applies to teachers as department employees with teaching duties. According to Fischer, Manstead, Evers, Timmers and Valk (2004), the display of desired emotions in the job does not necessarily cause negative side effects, presupposing that appropriate regulation of emotions is accepted as a part of teachers' role-identity. However, negative consequences may result if emotional dissonance occurs, since the expressed emotions do not coincide with one's identity. If teachers experience emotional labour over a sustained period, it could result in negative consequences, such as decreased satisfaction in the job, or burnout symptoms (e.g. emotional exhaustion) (Barber, Grawitch, Carson, \& Tsouloupas, 2010; Zhang \& Zhu, 2008). Emotional labour can also arise from the role of a teacher, a job or function that includes moral elements (Chen \& Kristjansson, 2011), such as pastoral care (Isenbarger \& Zembylas, 2006; Oplatka, 2007; Yuu, 2010) or being role models. From this perspective, it is pertinent that teachers as educators are in control of their emotions, which requires a degree of emotional labour.

Concluding, lack of competence in appropriate communication of emotion can not only damage the wellbeing of $\mathrm{HE}$ teachers but also endangers the development of positive relationships with students. Consequently, emotions and the display of emotions contribute to the quality of interactions (Boiger \& Mesquita, 2012). At university, interactions between teachers and students occur formally in courses and informally on campus. These interactions ultimately lead to the establishment of relationships, which are multilayered as they are built on a professional level (= working relationship) and on an interpersonal level (= closeness, affiliation) (Hagenauer \& Volet, 2014c; Nias, 1989). Richardson and Radloff (2014) have highlighted the significance of teacher-student-interactions for HE students' positive experiences, however they also cautioned that the frequency of direct interactions steadily decreases due to changes in the HE context (e.g. increases in student-staff ratio or online learning; as found in the Australian context). This development is alarming, given the fact, that fulfillment of the basic need for belongingness or relatedness (Baumeister \& Leary, 1995; Deci \& Ryan, 2002) is likely to be relevant for both - HE teachers (e.g. in terms of their workplace satisfaction) and HE students (e.g. in terms of their study commitment). 
As empirical evidence on the role of emotions in teacher-student interaction in HE is rather scarce, we draw from research on schoolteachers in order to better frame this phenomenon. From this research we know that interactions with students are frequently emotionally laden and that student-teacher-interactions are the most prevalent source of teacher emotions (for a review, see Sutton \& Wheatley, 2003). Recently, Hagenauer, Hascher and Volet (2015) have shown that "closeness" (as a result of many positive studentteacher interactions) to students (e.g., liking students; knowing them personally to some degree) predicted teachers' emotions experienced when teaching in the classroom. The effect was particularly strong for the experience of joy. More generally, the model on teacher emotions developed by Frenzel (2014) suggests, that teachers' perceptions regarding the degree of goal attainment in particular teaching and/or interaction situations with single students, groups of students or classrooms, determines the quality of the emotion evoked. Frenzel's model relies on an appraisal-theoretical approach to emotions and shows overlaps with the control-value theory of achievement emotions, which is primarily applied in research on students' emotions (Pekrun, 2006). According to that model, a teacher might experience anger if students are unengaged in class, on the expectation that participation is linked to high achievement goals, performance and motivation.

Furthermore, it is reasonable to assume that teachers and students' emotions are dynamically linked. Students are expected to react sensitively to their teachers' emotions, and reciprocally teachers would typically notice the emotional state of their students (Garner, 2010). This was demonstrated in a study by Frenzel, Goetz, Luedtke, Pekrun and Sutton (2009), which revealed that teacher's joy supported schoolstudents' enjoyment in learning. In the HE context, Titsworth, McKenna, Mazer and Quinlan (2013) detected a link between teacher immediacy, a quality indicator of a positive nonverbal teacher-student interaction, and positive student emotions. The phenomenon of emotions that spread from person to person is termed "emotional contagion" (e.g. Hatfield, Bensman, Thornton, \& Rapson, 2014).

Thus, the quality of teacher-student interactions in the classroom is highly relevant for the concrete emotional experiences of the actors involved. However, empirical evidence on emotions and emotion display in teacher-student interactions in HE, and more specifically in teacher education, is lacking. With regard to teacher education, some research has focused on the emotions of student teacher in the teaching practicum (e.g., Hascher \& Hagenauer, 2016; Pillen, Beijaard \& den Brok, 2013; Timostsuk \& Ugaste, 2012) or school-based teachers (Hastings, 2008); but the emotional aspects of the university-based part of teacher education are overlooked.

\subsection{Cultural aspects of emotion display and relationships}

Cross-cultural comparisons in emotion research are not new (e.g. Eid \& Diener, 2001). According to Mesquita (2007), emotions are "culturally situated" (p. 410) and are not just an individual phenomenon. Emotions can be described as socio-cultural phenomena since most human emotions are evoked in social situations of interaction (Boiger \& Mesquita, 2012).

Many studies of emotions across cultures have focused on the expression of emotions in social situations, which are underpinned by so-called display rules. For Safdar et al. (2009, p.1), display rules "influence the emotional expression of people from any culture depending on what that particular culture has characterized as an acceptable of unacceptable expression of emotion". Besides personality traits that affect emotion display (e.g. people with high scores on extraversion display emotions more intensively; Matsumoto, 2006), culture has been claimed to be an influencing factor on emotion display. In countries categorized as "individualistic" (Hofstede \& Hofstede, 2005), where a strong independent self is highly valued, different modes of emotion display can be observed in comparison to countries labeled "collectivistic", where an interdependent self is encouraged (Markus \& Kitayama, 1991). Despite evidence that the display of (negative) emotions is regarded as the right of the individual in "individualistic" countries, from a collectivistic point of view, emotions tend to be controlled in favor of the enhancement of positive relationships and harmony (Safdar et al., 2009). Furthermore, in countries labeled "individualistic" people have been found to value high intensive positive emotions (e.g. excitement), whereas people in more 
collectivistic cultures strive for the experience of low(er) intensive positive emotions (e.g. feeling calm) (Tsai, Knutson, \& Fung, 2006). Based on Hofstede and Hofstede's research (2005), Western countries, such as the U.S., Australia and many European countries, are considered "individualistic" countries, and East Asian countries as "collectivistic". However, such a broad-brush categorization has been widely criticized, given that there is great variability within cultural dimensions, including in terms of emotion display (Schwarz \& Ros, 1995). Consequently, there is a need for extending our understanding of emotion display rules within, and not only between, individualistic and collectivistic countries, which has been largely unexplored to date (see also Koopman-Holm \& Matsumoto, 2011, comparing the U.S. with Germany).

Furthermore, in HE, teachers act in a professional setting that has its own display rules. While emotions must be more controlled in workplace settings in comparison to private settings (Moran, Diefendorff, \& Greguras, 2013), another dimension requiring attention in cross-cultural emotion display research is that of context, and the roles people play and relationships they form in particular contexts. Therefore in addition to potential variability of emotion display within so called "individualistic" and "collectivistic" countries, the context and situation should be considered (see also Volet, 2001). An actor will vary in emotion display depending on the current role, as mother/father or university lecturer for example, and will also be impacted by the particular relationship quality. As Safdar et al. (2009) observed, the display mode of emotion is usually contingent on the interaction partner, this interdependency having consequences for the relationship, due to the reciprocal influence of emotion display and relationship-quality (Boiger \& Mesquita, 2012; Eid \& Diener, 2001; Fischer \& Manstead, 2010). Concluding, similarly to the display of emotions, the quality of the TSR is influenced by cultural and institutional (organizational) norms, functioning as cultural guidance modeling "ideas, meanings, and practices of how to be a person and how to relate to others" (Boiger \& Mesquita, 2012, p. 224).

\subsection{The present study: Aims and relevance}

The present study explored how Australian and German university teachers, in so-called "individualistic" countries, displayed their positive and negative emotions when teaching at university and how they perceived a positive TSR. The review article of Quinlan (2016) on HE teaching and learning underpins the importance of relationships for emotions in interactions and vice versa, which stresses the need for more empirical research on that issue. Furthermore, this study aimed to deepen understanding about university teachers' emotion display through a cross-cultural lens. This research is timely given the pace of HE's internationalization (Altbach \& Knight, 2007) in both research and teaching (e.g., Shimmi, 2014). Understanding the cultural specifics of both home and host country appears imperative for cultural adaptation, and the quality of teaching practice from an international perspective. More specifically, the following research questions were addressed:

a) What do German and Australian teacher educators perceive as appropriate emotion display in terms of positive and negative emotions when teaching and interacting with their students? What are similarities and differences in their perceptions?

b) How do German and Australian teacher educators construe the quality of the TSR, and the "ideal TSR"? What are similarities and differences in their views?

c) How do German and Australian teacher educators' modes of emotion display and views of the quality of the TSR quality interrelate?

d) How do particular background variables (e.g. position at university, background as a school teacher) contribute to explain the mode of emotion display and views of the quality of the TSR among Australian and German teacher educators?

The choice of samples within the individualistic cluster was based on convenience, and represent the authors' respective, personal cultural background and familiarity with specific cultural-educational HE contexts. However, this choice also addresses concerns that cross-cultural comparisons should go beyond the frequently made broad discrimination of collectivistic versus individualistic countries. Indeed, the two 


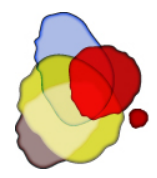

individualistic countries chosen for the present study score differently on Hofstede and Hofstede's (2005) degree of individualism. Based on their "individualism index" (p. 78), Australia ranks higher on individualism ( 2 out of 74 countries/regions) compared to Germany (ranked 18). Consequently, it was reasonable to anticipate some variability in display practices as well as perceptions of quality TSR, which could be interpreted in regard to their respective cultural-educational contexts (cultural and educational dimensions being confounded).

\section{Method}

\subsection{The participants}

Fifteen Australian (6 male, 9 female) and nine German (5 male, 4 female) teacher educators from two public universities in Australia and one public university in Germany participated voluntarily in the study. Participants for the study were approached informally by one of the authors from the same culturaleducational context. Selection criteria aiming at achieving representativeness in terms of relevant demographic characteristics pertaining to the population of teacher educators were: (1) at least two years of teaching experience (as there is evidence that the emotional experiences of beginning teachers are of particular quality, e.g. Ria, Sève, Saury, Theureau, \& Durand, 2003); (2) teaching in different subject areas across teacher education, for example, introductory courses in educational psychology, school pedagogics, mathematics and science education, civic education, and literacy education (as different subject areas may attract different styles of "communication"); (3) holding different positions in the university, ranging from full professor, to (full-time; part-time) lecturer, to $\mathrm{PhD}$-student with teaching duties (as particular positions in the university system are known to determine HE teachers' duties, and in turn the relative importance they give to teaching, frequency of interactions with students etc.). This purposive sampling strategy captured the typical heterogeneity of the population of teacher educators in these two countries, which is necessary for exploring the phenomenon in its breadth.

The Australian sample comprised twelve lecturers in teacher education (e.g., associate lecturer, senior lecturer, lecturer; most of them at post-doctoral level), and three Associate Professors in Education with broader teaching and research responsibilities. In contrast, the German sample consisted of five full Professors, one full-time lecturer, one post-Doctoral fellow, and two PhD students with teaching duties. The cultural-educational background of participants differed across countries The Australian sample was culturally more diverse than the German sample, which is typical of the profile of German and Australian teacher educators in general. None of the German teacher educators had any personal or professional experience of another cultural-educational setting, whereas five Australian teachers came from another country. However, these teachers had already some years of teaching experience in Australia before the interview was conducted. To protect the anonymity of the Australian participants, no details pertaining to their specific cultural background can be provided.

\subsection{The context: Teacher education in Germany and in Australia}

Teacher education in Germany is structured in two main phases. Phase 1 covers predominantly academic studies at a university (in general for 6 to 10 semesters), including some phases of school practice. However, most of the practical preparation is provided in a second phase, taking place in special, generally small, institutions operated by state governments and known as Studienseminare. The second phase typically lasts 24 months (König \& Blömeke, 2013). The present study took place in the first phase of teacher education at a University in Thuringia. No selection procedures (numerus clausus) for entry into teacher education are applied at that university. Thus, all students who had successfully completed their Abitur, the 


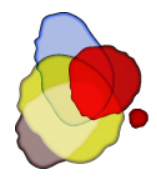

secondary school completion diploma, were qualified to commence teacher education. Students at that university studied teacher education to practice in high-track secondary schools, so called Gymnasien or Realschulen. Typically, most of these students have an academic family background and are not from a low SES or migrant family background.

Teacher education in Australia is structured differently, depending on whether it prepares students to become primary school teachers, or secondary school teachers specializing in the teaching of particular subjects, e.g. mathematics, languages, science. In the two universities where the study was conducted, students taught by the respondents were predominantly future primary school teachers. Primary teacher education, for students coming straight out of high school (the majority), is usually completed in a four-year period. Academic subjects are typically interspersed with practical preparation during the first three years with a strong practicum component in the last year. Entry into primary teacher education is based on academic results in high school, or completion of other tertiary study, but entry levels tend to be lower than in other fields of university study. A substantial proportion of future primary school teachers, taught by the respondents at these two universities, would have been from a low SES, and possibly migrant family background, although primary school teachers in Australia are not a culturally diverse professional group, which contrasts somehow with the overall diverse population.

\subsection{Interviews and procedure}

The first author conducted semi-structured face-to-face individual interviews with the teachers in each country. The style of the interviews was open, informal and conversational. University ethics approvals and informed consent from participants were obtained prior to participation. Most of the interviews were conducted in the interviewee's offices on campus, and a few in the staff room, if the teachers preferred this more informal context. Interview duration ranged from 35 to 75 minutes; most interviews were 45-55 minutes. Interviews were digitally recorded and transcribed verbatim. In the Australian context, the interviews were in English; in the German context they were in German. A German speaking person proficient in English translated the quotes used in the present article. For crosschecking, an English speaking person with sound German language skills did the same, leading to English transcriptions of the German interview accounts.

A semi-structured interview guideline framed the basic three themes that were addressed during the interviews: (1) emotions when teaching; (2) emotion regulation (internal regulation and emotion display) and (3) the TSR at university. In this paper, we refer to the interview accounts on theme 2 - focusing on the display of emotions - and theme 3 - the TSR. Emotional and relationship issues can be addressed directly or indirectly in the interviews. In our study, and consistent with ethical standards in qualitative research, the purpose of the research was communicated to the participants right from the beginning and participants were asked direct questions pertaining to the main focus of the research. Thus, the participants were fully aware that the interview would focus on emotions and relationships with students in HE. In other words, there was no artificially masking the central topics through indirect questions. Furthermore, we expected these experienced teacher educators would have reflected on their teaching and would feel ready to talk about their emotions and relationships with students. In terms of emotion display, the leading question was "Do you show and express your feelings while teaching and interacting with students or do you also hide them sometimes?" followed by various probes that included descriptions of concrete interaction situations that were experienced by the teachers in teaching situations, focusing on teaching in small-groups settings, such as seminars or workshops (up to about 30 students), and teaching first-year students. The teachers also talked about concrete emotions, e.g. joy or anger. If these accounts included information about the display of emotions, they were coded within the category "emotion display" as well. Regarding the TSR, teachers were asked to describe the "ideal" TSR at university from their perspective. Again, probes were used to elicit further elaboration on the TSR. If descriptions of emotional interaction situations contained details pertaining to the TSR, these accounts were coded within the category of TSR as well. 


\subsection{Data analysis}

The interview material was coded based on a category system in orientation to a deductive-inductive qualitative content analysis (Mayring, 2000; Gläser-Zikuda \& Mayring, 2003). The analysis involved several steps.

Step 1: First, a theoretically based category system was developed to code the content of the interviews. Then, the transcripts were read several times, and all text passages that could be allocated to the broad category of "emotion display" (subcategories: display of positive emotions versus display of negative emotions) or "the ideal TSR" were electronically coded using the MAXQDA software ("structuring content analysis" according to Mayring, 2000). This step was done by the first author only, as due to the direct question format the extraction of these interview accounts was a very clear coding process with little room for interpretation. The three main codes - illustrated in Table 1 - were derived deductively from the theory and the main research questions. To ensure an objective and reliable coding procedure, coding rules were formulated and anchor examples identified in the interviews.

Table 1

The coding scheme

\begin{tabular}{|c|c|c|}
\hline Code & $\begin{array}{l}\text { Number of } \\
\text { accounts }\end{array}$ & Code description and anchor example \\
\hline $\begin{array}{l}\text { Displaying } \\
\text { positive } \\
\text { emotions }\end{array}$ & $\begin{array}{l}\text { AUS: } 46 \\
\text { GER: } 28\end{array}$ & $\begin{array}{l}\text { This code is used when teachers talk about how to display positive emotions. } \\
\text { Example: So, okay, the positive ones are easy to handle. Just join it, just share the } \\
\text { fun. }\end{array}$ \\
\hline $\begin{array}{l}\text { Displaying } \\
\text { negative } \\
\text { emotions }\end{array}$ & $\begin{array}{l}\text { AUS: } 80 \\
\text { GER: } 60\end{array}$ & $\begin{array}{l}\text { This code is used when teachers talk about how to display negative emotions. } \\
\text { Example: Uhm, probably. I am sure I do. I am a bit of an open book. So, I think, you } \\
\text { know, I don't ... I don't hide my feelings or even though I try to ... As I've said I am } \\
\text { not gonna show that I am angry. }\end{array}$ \\
\hline $\begin{array}{l}\text { The quality of } \\
\text { the TSR }\end{array}$ & $\begin{array}{l}\text { AUS: } 69 \\
\text { GER: } 24\end{array}$ & $\begin{array}{l}\text { This code is used for teachers' answers on the question pertaining to "ideal TSR". } \\
\text { No distinction is made between the professional and interpersonal TSR at this coding } \\
\text { step, as statements on both dimensions are frequently intertwined. } \\
\text { Example: I am careful, because I don't want it to seem unprofessional. But yeah, I } \\
\text { also think it's important for them to see that ... It's a whole person. }\end{array}$ \\
\hline
\end{tabular}

Step 2: After that, and in order to get greater insight into each individual teacher and his/her perception in terms of negative and positive emotion display and the TSR, a summary for each interviewee was prepared based on the extracted interview accounts resulting from the first coding step ("summarizing content analysis"; Mayring, 2000). These summaries provided a concise overview of each case (or HE teacher educator). After that, the original interview accounts and the summaries formed the basis for coding each case according to the relevant categories. A separate coding scheme for negative emotion display, positive emotion display and the TSR was applied to each case as the unit of analysis.

[1] In terms of the display of negative emotions (= anger), three aspects were coded:

a) Did the teacher perceive the direct communication of anger as appropriate or not? (1=yes; 2 =no; 3 = ambivalent)

b) Did the teacher think that the communication of anger has to be controlled? $(1=$ yes; $2=$ no; 3 = ambivalent)

c) How does the teacher communicate his/her anger to the students? $(1=$ I-messages; $2=$ group-messages; $3=$ transfer messages; $4=$ argumentative confrontation; $5=$ provocative confrontation; $6=$ sarcasm, irony; $7=$ raising the voice; $8=$ threat $/$ 
classroom relegation; $9=$ one-on-one contact after the lesson; $10=$ I-messages (using less intensive words)

While the codes 1 and 2 were derived deductively, the codes applied in (3) (= communication of anger) were inductively developed from the data.

[2] In terms of the display of positive emotions, two aspects were coded:

a) Did the teacher perceive the direct communication of positive emotions as appropriate or not? $(1=$ yes; $2=$ no; 3 = ambivalent $)$. As not many accounts revealed information on the control of positive emotions, the code "emotion control" was not applied for the display of positive emotions.

b) How does the teacher communicate his/her positive emotions? (1= positive feedback (neutral); 2 = praising students; $3=$ communicating positive emotions intensively (verbally); 4 = hugging students; 5 = displaying enthusiasm; 6 = sharing humour).

Again, code 1 was derived deductively from theory, and the concrete emotional communication inductively from the data.

[3] In terms of the ideal TSR two codes were applied:

a) Does the teacher perceive the professional aspect of the TSR as relevant? $(1=$ yes, 2 = no, 3 = ambivalent)

b) Does the teacher perceive the interpersonal aspect of the TSR as relevant? $(1=$ yes, $2=$ no, $3=$ ambivalent)

Both codes were derived deductively according to the conceptualization of the TSR (Hagenauer \& Volet, 2014c). As an example, the coding scheme for the display of positive emotions is illustrated in Table 2. 
Table 2

The coding scheme for the display of positive emotions

\begin{tabular}{|c|c|}
\hline Code & Anchor example \\
\hline \multicolumn{2}{|c|}{ Direct expression of positive emotions } \\
\hline Yes (1) & $\begin{array}{l}\text { "Yes" is coded, if teachers say that they communicate positive emotions to } \\
\text { students. }\end{array}$ \\
\hline No (2) & $\begin{array}{l}\text { "No" is coded, if teachers do not communicate their positive emotions to } \\
\text { students. }\end{array}$ \\
\hline Ambivalent (3) & $\begin{array}{l}\text { "Ambivalent" is coded if teachers basically agree that showing positive } \\
\text { emotions is possible, but are hesitant about it at the same time. }\end{array}$ \\
\hline
\end{tabular}

Way of communicating emotions

Giving positive feedback (1) The teacher communicates positive emotions neutrally by giving contentfocused feedback.

I give feedback to the students at the end of the session how I perceived the session. How I perceived the progress of the course. (I5, Germany)

Praising students (2)

Expressing positive emotions intensively (verbally) (3)

Hugging students (intense physical reaction) (4)

Displaying enthusiasm (5)

Sharing humour (6)
The teacher communicates positive emotions (e.g., satisfaction) by praising the students. Praise incorporates some kind of emotionality in the feedback.

The teacher communicates positive emotions intensively verbally. The communication is more intensively compared to code 2 .

The teacher hugs the students. the content / subject.

The teacher shares humour in the classroom.
Well, from my perspective praising students is very important. (I6, Germany)

I would equally say "I am so happy for you." You know, if somebody gets a job or if somebody gets an award or something else. (I4, Australia)

I would hug students and students would hug me that ... that ... not all the time but I wouldn't hold back from doing that kind of thing. (I4, Australia)

I get excited about things. And I'll say: Oh, guess what, guys! Look at this! Check this out! Everybody come over! (I13, Australia)

Having a laugh with the group. That's important. (I15, Australia)

Interrater-reliability was calculated for the second coding step. Interview accounts from eight interviewees (four from Germany, four from Australia), which represents about a third of the whole data set, were randomly selected and coded independently by two of the authors. Both are fluent in German and English, which was critical as the German interviews were not translated to English. The result of the double-coding procedure is presented in Table 3. Percentage agreement was $92.60 \%$ (54 coding options; 4 disagreements). In order to account for randomly reached agreement, the corrected Cohen's kappa was calculated (Brenan \& Prediger, 1981). It lied at .85, which is satisfactory (Bortz \& Döring, 2006). All disagreements were discussed between the two coders (including also going back to the whole interview incorporating any information that would help to clarify the respective code) until agreement was reached. After that, the first author went back to the data and validated the codes of the other interviews taking into account the aspects that had been discussed between the two coders. 
Table 3

Interrater agreement (selection of 8/24 teacher educators, 4 German and 4 Australian)

\begin{tabular}{|c|c|c|c|c|c|c|c|c|}
\hline & GER1 & GER2 & GER3 & GER4 & AUS1 & AUS2 & AUS3 & AUS4 \\
\hline Display of positive emotions & $\mathrm{x}$ & $\mathrm{x}$ & $\mathrm{x}$ & $\mathrm{x}$ & $\mathrm{x}$ & $\mathrm{x}$ & $\mathrm{x}$ & $\mathrm{x}$ \\
\hline Display of negative emotions & $\mathrm{x}$ & $\mathrm{x}$ & $\mathrm{x}$ & $\mathrm{x}$ & $\mathrm{x}$ & $\mathrm{x}$ & $\mathrm{x}$ & $\mathrm{x}$ \\
\hline Interpersonal teacher-student relationship & $\mathrm{x}$ & $(\mathrm{x})$ & $\mathrm{x}$ & $\mathrm{x}$ & $\mathrm{x}$ & $\mathrm{x}$ & $\mathrm{x}$ & $\mathrm{x}$ \\
\hline $\begin{array}{l}\text { Emotion control (display of negative } \\
\text { emotions) }\end{array}$ & $\mathrm{x}$ & $\mathrm{x}$ & $\mathrm{x}$ & $\mathrm{x}$ & $\mathrm{x}$ & $\mathrm{x}$ & $\mathrm{x}$ & $\mathrm{x}$ \\
\hline Communicating positive emotions (1) & $\mathrm{x}$ & $\mathrm{x}$ & (x) & $\mathrm{x}$ & $\mathrm{x}$ & $(\mathrm{x})$ & $\mathrm{x}$ & $\mathrm{x}$ \\
\hline Communicating positive emotions (2) & $\mathrm{x}$ & $\mathrm{x}$ & & & $\mathrm{x}$ & $(\mathrm{x})$ & $\mathrm{x}$ & $\mathrm{x}$ \\
\hline Communicating positive emotions (3) & & $\mathrm{x}$ & & & & & & \\
\hline Communicating negative emotions (1) & $\mathrm{x}$ & $\mathrm{x}$ & $\mathrm{x}$ & $\mathrm{x}$ & & & $\mathrm{x}$ & $\mathrm{x}$ \\
\hline Communicating negative emotions (2) & & & & $\mathrm{x}$ & & & & \\
\hline
\end{tabular}

Note. $\mathrm{x}=$ agreement; $(\mathrm{x})=$ disagreement; empty field $=$ n.a., if for example, an interviewee only mentioned one way of communicating positive emotions.

Step 3: The final step complemented the comparison of emotion display modes and the quality of the TSR across the two countries based on the interview accounts extracted in coding step 1 and the case summaries resulting from coding step 2. Regularly revisiting the original transcripts was undertaken at step 3 in order to confirm the accuracy of inferred conclusions. Step 3 resulted in a case overview pertaining to the three main categories, namely, "display of negative emotions", "display of positive emotions" and the "ideal TSR".

\section{Findings}

As aforementioned in the introduction, emotion display and relationships are reciprocally entwined. The findings are structured around the four research questions, (1) starting by German and Australian teacher educators' perceptions of appropriate emotion display in their interactions with students, (2) followed by their views of the quality of the TSR at university and the "ideal TSR", (3) the relationship between their reported modes of emotion display and views of the quality of the TSR, (4) and the examination of background variables that may contribute to explain modes of emotion display and views of the quality of the TSR across samples.

\subsection{Modes of emotion display $(\operatorname{Res} Q \mathbf{1})$}

\subsubsection{Modes of positive emotion display}

Across interviews, teacher educators stressed issues concerning the display of positive emotions less frequently than the display of negative emotions. For most, it was clear that positive emotions evoked in the classroom are shared easily, although the majority of German teacher educators appeared more reluctant in expressing positive emotions in an (emotionally) intense and direct manner than their Australian counterparts. Australian teacher educators frequently expressed strong positive feelings about students, as illustrated by emotionally laden expressions, such as "being thrilled about" or "getting very excited in the classroom". In contrast, German teacher educators reported expressing positive emotions less directly, mainly communicating their satisfaction or joy by praising the achievement of particular students or a group. When probed about displaying positive feelings in the classroom, German teacher educators mostly tended to respond in a way similar to this example: 


\section{I: "And how about the positive emotions? Do you express them as well?" \\ A: „, Yes, it is very similar. At the end of each course I give feedback how I experienced it. (I5, male, Germany)}

Thus, in the German context positive emotions were typically reflected in teacher's feedback or praise, and commonly communicated in a relatively neutral manner. Alternatively, the Australian teachers reported more emotion-laden interactions in expressing praise. For example,

\section{So I have sent an announcement to everyone saying, I am really thrilled and proud of the feedback you are giving on your (anonymized; virtual platform). (I8, male, Australia)}

A female Australian teacher also mentioned that she would hug students if she felt deep joy, e.g. due to the success of a particular student. Further, some Australian accounts revealed how emotions transfer between teachers and students (e.g. a student feels happy following success; this happiness transfers to the teacher).

Taken together, it is clear that expressing positive emotions was widely regarded as appropriate and relevant (e.g., in terms of fostering students motivation) in both cultural-educational contexts. However, the actual mode of expression differed somewhat across contexts. This pertained mainly to the student-teacher interaction (e.g. how to praise students) and less to the teacher-subject-interaction (e.g., how to respond emotionally on subject matter). Australian and German teacher educators expressed relaying enthusiasm for their taught subject similarly, but a little more pronounced in the Australian context, as illustrated by the following quote:

\section{I mean, I get excited about things. Very enthusiastic about the science. And I'll say: Oh guess what, guys! Look at this! Check this out! Everybody come over! (imitates excitement in a classroom). Now, is that emotional? Yes! I get very enthused about the science or you know, that type of thing. It's really cool stuff. But as far as reacting to students, I try not to be way up or way down. (I13, female, Australia)}

Finally, what was perceived as appropriate display of emotions varied among teachers from the same country, indicating that the expression of emotions may be influenced not only by the cultural-educational context but also by individual characteristics, such as personality or position at university. For example, contrary to most of her colleagues, one German teacher reported teaching in a very emotional manner, as she had experienced that kind of enthusiasm as a relevant antecedent of learner's motivation during her former work as a schoolteacher.

\subsubsection{Modes of negative emotion display}

In terms of negative emotions, annoyance dominated in both the German and Australian accounts. Therefore the following analysis focused on teachers' annoyance and anger (for an overview on the range of negative and positive emotions typically expressed by teacher educators, see Hagenauer \& Volet, 2014a).

In the present study, we focused on the most frequently mentioned negative behaviours that evoked teachers' anger or annoyance (e.g. student disengagement or classroom disturbance). Comparing case summaries revealed a marked difference in the accounts of the German and Australian teachers. While nearly all the Australian teachers shared the opinion that negative emotions should be suppressed for professional and role-modeling reasons, German teachers were less reluctant in expressing their anger directly to students. But both groups shared the belief that the display of anger should be controlled according to professional standards. More concretely, most Australian teacher educators advocated for the need to suppress negative feelings in class. If classroom disturbances occurred, both groups claimed that the teacher should intervene calmly if the disturbance affected the learning of the others but would strategically ignore the disturbance if the classroom learning process were not endangered. They usually would not express negative emotions directly, but would talk to the particular student(s) on a one-on-one basis in or after the course to address the problematic behavior: 
But if they talk to each other, I would mention that. Yeah, I would say: I would expect you, you know, you are listening at this point. I try and do that sometimes in a private way rather than publicly. (II4, male, Australia)

In contrast, the German teacher educators reported a variety of reactions when they experienced anger, which were made visible to students more pronounced relative to their Australian counterparts. For example, one German female teacher reported that she experienced anger if students submitted assignments the evening before the seminar. Upon probing how she expressed her anger, she replied:

\section{I tell them, it is not ok, if they don't get the timing right and I have to pay for it. It's not acceptable for me. I don't want that and then I also justify why I don't want it that way. (I9, female, Germany)}

Only one of the nine German teacher educators said he suppressed his anger completely, which he traced back to his personality and his difficulty in coping with conflict. The other German teacher educators reported using mainly verbal strategies in such circumstances, such as sending I-messages addressing problematic behaviour and how it affected them ("I am annoyed that..."), or the group ("Do you think it is fair to your group members...?"), or asking the students how they would cope with such situations in their own classroom (bringing in the professional perspective). I-messages were also a popular method to deal with disturbances from the Australian teachers' perspective. If perceived as necessary, problems were also addressed verbally; however experienced negative emotions were frequently addressed more cautiously, by substituting with a less-intense emotion display. For example, one teacher reported dealing with anger and disappointment in class contributions:

\section{I mean, if you're disappointed, if you are not happy with something, you have got to tell them. And I'll tell them. If I say: Look, I am not, I am not pleased. Nobody seems to be contributing to this discussion today. We need to contribute to discussions. This is how we learn. We need to talk about things. So, you know, please get involved." (I9, male, Australia)}

When students expressed opposing views, or displayed lack of openness, which caused anger in some of the German teachers' accounts, the German teachers frequently dealt with their annoyance through starting an argumentative and sometimes provocative discussion in class. Some teachers also reported raising their voice or using sarcasm as verbal reactions in situations they found annoying. One teacher mentioned that he was willing to react directly by removing the problematic student from the classroom if the student did not respond favorably after a few prompts.

Some reactions to anger that were mentioned by the German teacher educators would be perceived as problematic in the Australian context. For example, the display of anger was interpreted as a means of maintaining a productive professional working relationship from some German teachers' perspective, since not displaying anger, and not intervening in difficult classroom situations would be regarded in that context as displaying a lack of professionalism. It should be noted, however, that such views were mainly expressed by less experienced teachers. In contrast, one Australian teacher stated that he "would lose face" if he showed his annoyance directly in class. Another Australian teacher mentioned that he did not want to risk the progress of the work by letting negative emotions interfere while another female Australian teacher said she would not want to risk the positive relationships with students by reacting angrily.

Figure 1 and 2 and Table 4 outline the findings pertaining to the overall display and communication of positive and negative emotions. Each teacher educator is listed as a case in the table and is represented within one column. In the Figures the percentage of cases within each group of teacher educators (German, Australian) is provided. The calculation of the percentage made it possible to compare the responses of German and Australian teacher educators directly as within each group - although based on a different 
frequency - they finally summed up to $100 \%$. Thus, in the Australian sample a teacher educator accounts for about $7 \%$; in the German sample for about $11 \%$.

As can be seen, German and Australian teacher educators shared many ways of displaying their emotions in the classroom, but there were also noticeable differences. German teacher educators frequently reported direct display of anger but this was not the case among the Australians. In contrast, the direct display of positive emotions was slightly more pronounced within the Australian compared to the German sample. The German teacher educators also reported higher intensity of direct anger display and also a higher variety of possible responses. In particular, German teacher educators reported using various forms of verbal reactions when facing difficult student behaviour, while their Australian counterparts tended to avoid direct confrontation and preferred talking to their students after class one-on-one. Verbal and rational reactions, termed as "positive feedback", also seemed to be the German teachers' preferred way of displaying positive emotions, while the emotional aspect of feedback/praise came through emotionally more intensely in the Australian teachers' accounts.

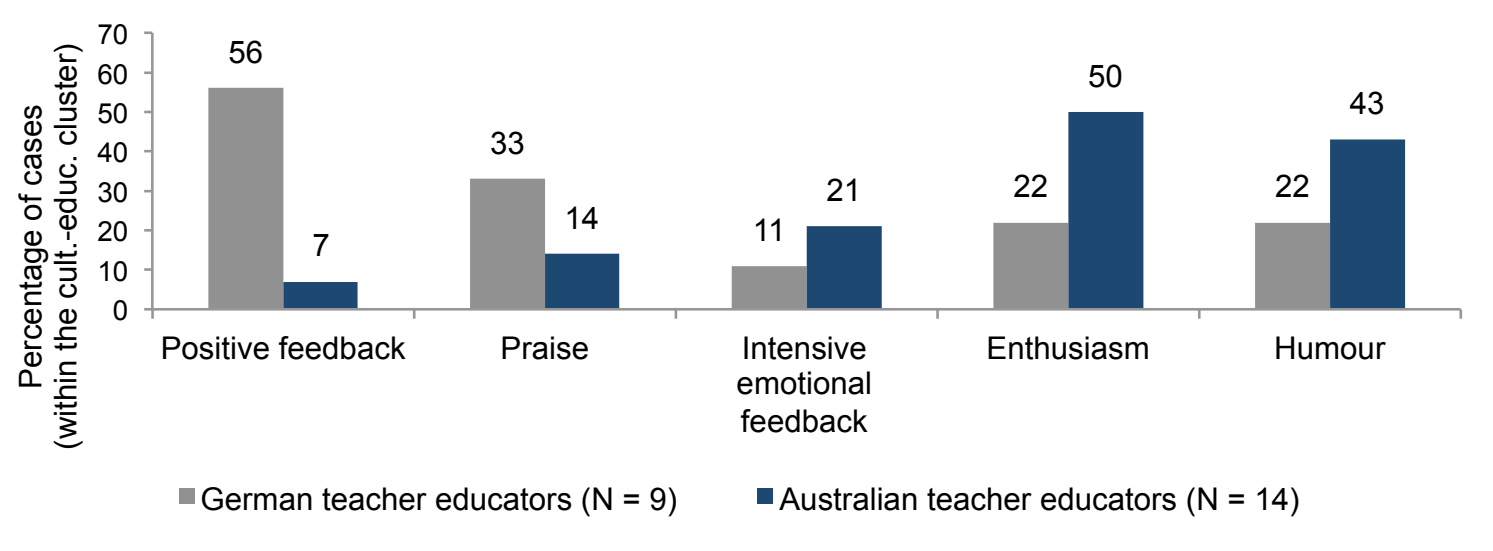

Figure 1: Ways of communicating positive emotion by German and Australian teacher educators

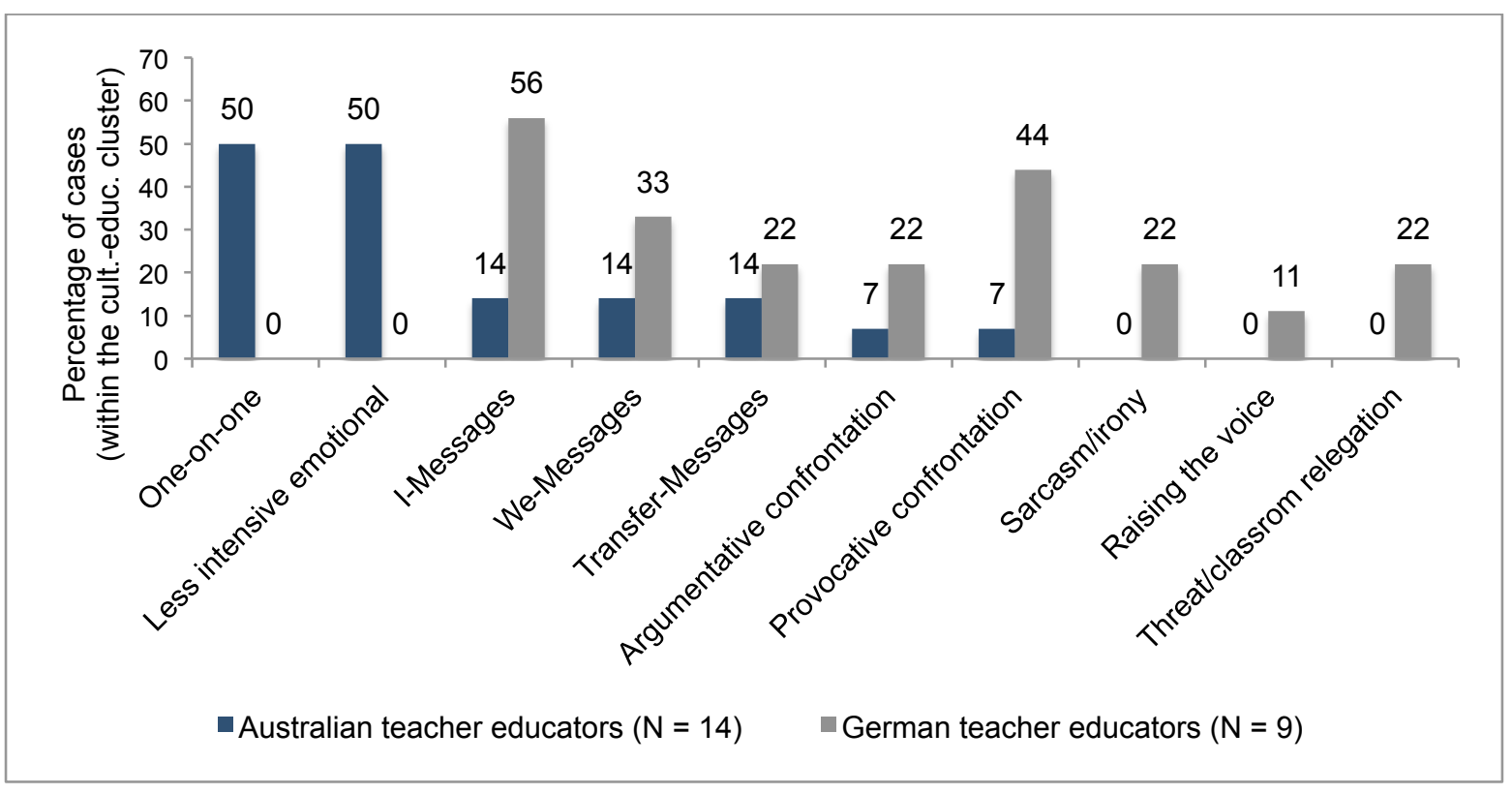

Figure 2: Ways of communicating anger by German and Australian teacher educators 
Table 4

Display of positive and negative emotions: Case overview comparing German and Australian teacher educators' perceptions

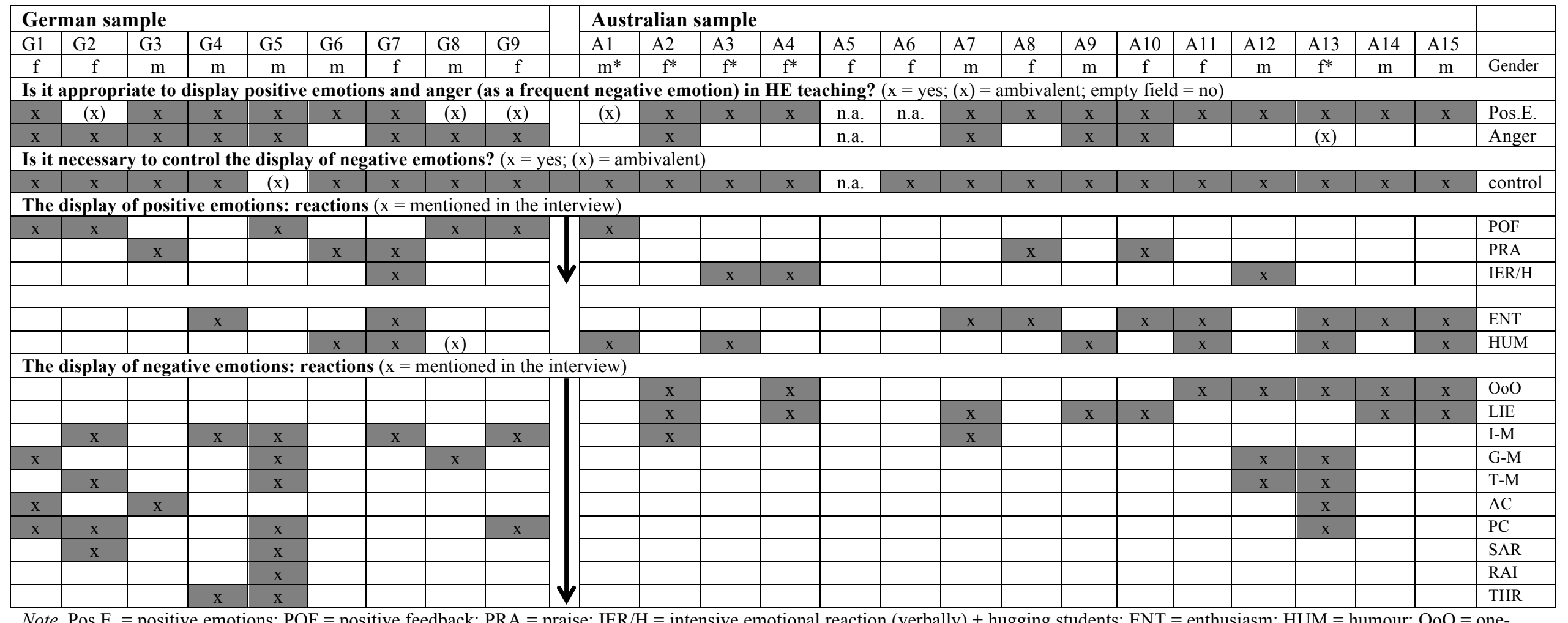

Note. Pos.E. = positive emotions; POF = positive feedback; PRA = praise; IER/H = intensive emotional reaction (verbally) + hugging students; $\mathrm{ENT}=$ enthusiasm; $\mathrm{HUM}=$ humour; OoO = oneon-one contact after the lesson; LIE = using less intensive emotion words; I-M = I-messages; G-M = group messages; T-M = transfer messages; AC = argumentative confrontation; $\mathrm{PC}=$ provocative argumentation; $\mathrm{SAR}=$ sarcasm/irony; $\mathrm{RAI}=$ raising the voice; $\mathrm{THR}=$ threat, classroom relegation; n.a. $=$ not applicable (no information on that aspect in the interview): * coming from another cultural background;

$\rightarrow$ The arrow represents an increasing intensity of the respective emotional reaction; e.g. in terms of anger: talking one-on-one privately after the lesson (OoO) is less intensive than directly addressing the problematic behaviour in class (e.g. through I-messages; LIE; I-M); in terms of positive emotions: giving neutral feedback (POF) is less intensive than praising students (PRA) 


\subsection{Quality of the teacher-student relationship (Res Q 2)}

According to Hagenauer and Volet (2014c) the quality of the TSR can be described in terms of support (or professional) dimension or in terms of affective (or interpersonal) dimension. Our findings are presented in relation to these two dimensions, starting with the teachers' views on the quality of the professional TSR.

\subsubsection{The professional teacher-student relationship}

By comparing the accounts and reflections of the Australian and German teacher educators, it is evident that both groups regarded the TSR as predominantly a professional one, with particular boundaries that must not be overstepped, but with "room to personalize" this relationship, as stated by one Australian female teacher educator (I5). However, there were also differences between the two groups of teachers, particularly with regard to the amount of formality versus informality of the interactions, and the amount of (interpersonal) care expressed within this relationship.

Most of the German teacher educators described their role within the professional TSR mainly as being a moderator, a generator of ideas and inspiration or a specialist in terms of the teaching content, who designs effective learning environments in which students are required to contribute actively. This professional TSR understanding is illustrated below:

I would like to be an instigator. I want to challenge them, they should think about stuff, care about things, which I think are relevant, yes, be an inspiration, a person who challenges, you know...the person, who asks good questions and starts new thinking processes. I'm not a

Guru. I can see that with some colleagues and that's scary to me, you know, to have something like a fan club. I'm not the head-teacher. I'm more the person who asks questions. An instigator. (I9, female, Germany)

In this professional working-relationship mutual appreciation and respect are important components from the teacher educator's perspective and a well-adjusted give-and-take basis is expected (e.g., in terms of engagement). A male professor called this kind of relationship "mutual receptiveness and openness" (I3). Furthermore, many German teacher educators also expressed approachability as a relevant dimension of the relationship, equalizing approachability mostly with openness for content-related questions of students. Informal contact between students and teachers apart from the regular course setting and the official officehours was rare. The following quote gives an example of a male teacher's perception on approachability, which also addresses the idea that a certain distance in the TSR might not only be a need of teachers but also of students:

The direct connection with students, if they [the students] want it, it's not a problem for me. In lectures I say to them: if you have questions or if you need anything else you can come and talk to me during office hours, or they can have an additional appointment. It's all possible. If

I have the time, I will give it to them. But it has to be in a, you know, professional setting. Well, it needs to stay connected to the topic. (I5, male, Germany)

In another interview a female university teacher-professor stressed that office hours must be kept, the dilemma being that good teaching is frequently unrewarded, which affects the amount of effort invested into teaching. Ultimately, this also impacts on the frequency and intensity of teacher-student interactions:

I plan 1.5 hours for the office hour, most of the time I need 2, I use a watch for it. Well, they would like to be looked after for half an hour. That's not possible. After 15 minutes they have 
to leave ... at the latest. They have to ask precisely. It's strange, but it feels that university teaching stops me from my work. [...] Umm, and it's not that I don't think that teaching is not important, it just feels, like doing something that nobody sees or doesn't count. That's the frustrating thing. (I9, female, Germany)

\subsubsection{The interpersonal teacher-student relationship}

Australian teacher educators emphasized mutual respect and appreciation as relevant characteristics of the TSR, but they considered its quality in terms of informality in interactions. Thus, within the interpersonal dimension of the TSR some sort of "closeness" is coming into play, as the following account reveals:

I think closeness... and caring is quite important. We routinely here, as you noticed, we are not status-bound. I introduce myself to my students as XY (first name). I say: Just call me XY (first name). And I want them to see me as someone who is here to help them, not someone who has an authority-status.[...] So, we have an ethos in tune. I think we've always had that.

$$
\text { (I7, male, Australia) }
$$

In contrast, "closeness" was viewed skeptically by most of the German teacher educators:

I would say, relationships between students and teachers or lecturers should always be at a professional level. Of course there are sympathies. There are aversions. They are okay and legitimate. But they musnt't disturb the sequence [of the course]. (I5, male, Germany)

As expected, these "relational" differences underpinned teacher-student interactions. In contrast to Germany, it was found that Australian students could call their university teachers by their first name, and many teachers reported an open-door policy, so students could approach them whenever they wanted to. It appeared also not unusual in the Australian context for teachers and students to share personal information, sometimes during the course but also anywhere on campus. A male teacher discussed his willingness in establishing interpersonal relationships:

I try and take an interest in them personally ...with their jobs and their families and the rest of their lives. And I try and make it clear that I am not just a teacher of [subject area]. I do other things as well. (I7, male, Australia)

Furthermore, for the Australian teachers, approachability implied that students could approach them when they had content-related questions, but also if they were dealing with personal issues that interfered with their study. Aspects of personal care that appeared to come into play were more visible in the interview accounts of the Australian teacher educators. This might be partly related to the fact that many students in the two Australian universities in the present study were from a lower socioeconomic background. During the interviews, a number of teacher educators expressed worry or concern about the study success of these students and expressed a willingness to listen to their problems, for example, by granting extensions in terms of submitting assignments and spending extra time one-on-one to discuss open questions.

And they have ...you know, there are lots of personal issues, particularly in a lower socioeconomic area ... [...] I generally find, that if someone has an issue and if you manage to build that rapport and that relationship they are happy to come and talk to me about it and to say, you know, that they're struggling because of being at the doctor last week and having heart tests and that they're, you know, are so stressed and not knowing what the results are 
and things like that...that, you know, I am happy to sort of say to them: Well, fine. This assignment is due in Friday night. Monday is fine. (I8, female, Australia)

Interestingly, when probed for worry or concern, many of the German teacher educators said that these emotions did not play any important role in their teaching practice.

But in a workshop or seminar, whether they achieve or not, I'm not too worried, because ultimately, they are adults and I can't do everything for them. (I2, female, Germany)

Not only the background of students, but also the system more generally appeared to contribute to the explicit caring attitude of teacher educators in Australia. As retention rate and learning outcomes of students are considered by funding bodies as important indicators of the "efficacy" of university teaching, these teachers felt somehow obligated to maximize students' academic success, which sometimes created friction:

It is hard, yeah. In Australia very much the emphasis is to try and help them to pass. And that's something I am not used to...because sometimes I think some students really need to fail.

(laughs). But you try and help them as best as you can. So, if they are struggling in language you'll offer them support in their language. But sometimes you think: Really, this person shouldn't be teaching! (laughs) Well I just, I sense that we are maybe a little bit softer than other countries. (I12, male, Australia)

Based on the informality of the TSR and the amount of care invested in this relationship, the interpersonal aspect of the TSR emerged not only as stronger in the Australian sample, but often as an explicit goal in teaching (e.g. building a rapport with students). The informality and caring attitude, highlighted by Australian teacher educators, was also occasionally questioned, but mainly by teachers from another cultural background, suggesting that such informality may have to be learned by new teachers:

Here are more informal kinds of relationships. But it doesn't mean...being informal does not mean that there is no distinction between workshop leader and students. I find it very hard to balance. It's sometimes informal. Okay, we are like equal, you know. We are like friends. [...] So I adapted to it and, yeah, I still need to, I am still learning. I feel, because it's a long drawn thing having to find a nice balance or effective balance. I don't have to be nice but I need to be effective. (II, male, Australia)

But not only the informality constitutes an aspect that new teacher educators may have to adapt to in the Australian context. The same may apply to the adoption of an explicit "caring attitude" as observed by non-native teacher educator, who described her local colleagues as follows:

Most of the lecturers here would have been teachers at some stage. So, most of them would come with that caring attitude. You know, wanting to establish good relationships, wanting to have, you know, like the best possible environment, where they can teach and their students can learn. (I2, female, Australia)

Taken together, these findings show that Australian and German teacher educators share a similar belief about the necessity to form professional relationships with students at university. However, due to differences in how interactions are realized - in particular due to higher informality and more pronounced caring attitude in Australia - the interpersonal TSR seemed to be closer in the Australian sample, while the professional and more formal working relationship dominated in nearly all of the accounts of the German teachers (see Table 5). 
Table 5

Case overview: The ideal teacher-student relationship (TSR): professional and/or interpersonal?

\begin{tabular}{|c|c|c|c|c|c|c|c|c|c|c|c|c|c|c|c|c|c|c|c|c|c|c|c|c|}
\hline & \multicolumn{9}{|c|}{ German sample } & \multicolumn{15}{|c|}{ Australian sample } \\
\hline & 1 & 2 & 3 & 4 & 5 & 6 & 7 & 8 & 9 & $1 *$ & $2 *$ & $3 *$ & $4 *$ & 5 & 6 & 7 & 8 & 9 & 10 & 11 & 12 & $13 *$ & 14 & 15 \\
\hline Gender & $\mathrm{f}$ & $\mathrm{f}$ & $\mathrm{m}$ & $\mathrm{m}$ & $\mathrm{m}$ & $\mathrm{m}$ & $\mathrm{f}$ & $\mathrm{m}$ & $\mathrm{f}$ & $\mathrm{m}$ & $\mathrm{f}$ & $\mathrm{f}$ & $f$ & $\mathrm{f}$ & $\mathrm{f}$ & $\mathrm{m}$ & $\mathrm{f}$ & $\mathrm{m}$ & $\mathrm{f}$ & $\mathrm{f}$ & $\mathrm{m}$ & $\mathrm{f}$ & $\mathrm{m}$ & $\mathrm{m}$ \\
\hline $\begin{array}{l}\text { Prof. } \\
\text { TSR }\end{array}$ & $\mathrm{X}$ & $\mathrm{X}$ & $\mathrm{X}$ & $\mathrm{X}$ & $\mathrm{X}$ & $\mathrm{X}$ & $\mathrm{X}$ & $\mathrm{X}$ & $\mathrm{X}$ & $\mathrm{X}$ & $\mathrm{X}$ & $\mathrm{x}$ & $\mathrm{X}$ & $\mathrm{X}$ & $\mathrm{X}$ & $\mathrm{X}$ & $\mathrm{X}$ & $\mathrm{X}$ & $\mathrm{x}$ & $\mathrm{X}$ & $\mathrm{X}$ & $\mathrm{X}$ & $\mathrm{X}$ & $\mathrm{X}$ \\
\hline $\begin{array}{l}\text { Interp. } \\
\text { TSR }\end{array}$ & & & & & & & $(\mathrm{x})$ & & & & & $\mathrm{x}$ & $\mathrm{X}$ & & $\mathrm{x}$ & $\mathrm{x}$ & $\mathrm{x}$ & & & $\mathrm{x}$ & $\mathrm{x}$ & $(\mathrm{x})$ & $\mathrm{x}$ & \\
\hline
\end{tabular}

*coming from another cultural background

\subsection{Relationship between modes of emotion display, quality of the teacher-student relationship and}

\section{cultural-educational background of teacher educators (Res Q 3)}

In a final step, three target factors were interrelated: (1) mode of emotion display; (2) quality of TSR and (3) cultural-educational background of teacher educators (see Table 6). In order to explain the relevance of the TSR on the display reactions of emotion, the differences in display modes within the group of German teacher educators and within the group of Australian teacher educators was of interest (= controlling for cultural-educational background). Looking at the Australian sample, it became clear that the teacher educators, whose TSR was more pronounced on an interpersonal level, displayed their positive emotions with higher intensity (marked in bold font, see Table 6); this was the same for the German teacher educator who also formed strong interpersonal relations with her students. Thus, for both cultural-educational groups the intense communication of positive emotions was strongly connected to the interpersonal TSR. In regard to the communication of anger, the Australian teacher educators communicated anger similarly, regardless of whether they had formed a strong interpersonal TSR or not. However, a slight difference appeared: Two of the teacher educators, who formed the TSR also on an interpersonal level, report using "moral" strategies when communicating their anger (we-messages; transfer messages). None of the Australian colleagues - who focused less on the interpersonal TSR - reported these strategies. Having a closer look at the German teacher educator with a more pronounced affective bond to her students, it became apparent that she used lessintensive anger reactions than some of her colleagues who adopted a greater distance and a less explicit caring attitude to their students.

In a second step, a comparison within the respective TSR group was made, in order to explore whether cultural-educational differences were still noticeable when accounting for the quality of the TSR. Within the group of teachers who formed strong interpersonal TSR, the German teacher educator showed similar reactions in terms of communicating positive emotions; but her display of negative emotions through I-messages was more directly compared to the main reactions of the Australian counterparts, who preferred mainly one-on-one contacts after the course/workshop. Within the group of teachers who formed the TSR mainly on a professional level, the obvious difference in the direct communication of anger and positive emotions between Australian and German teacher educators persisted: On a professional level, the German teacher educators communicated their positive emotions more neutrally, and their anger more directly than their Australian counterparts.

Thus, the results highlight two main points: First, an emphasis on the interpersonal TSR mainly goes along with the display of high intense positive emotions and less intense negative emotions. Second, differences in emotion display between Australian and German teacher educators were found also within the respective TSR grouping (professional + interpersonal, professional only), which points to the importance of cultural-educational background as an influencing factor on teacher educators' emotion display that goes above and beyond the quality of the TSR. 
Table 6

Case overview: Display of positive and negative emotions and quality of the TSR, taking teacher educators' cultural-educational background into account

\begin{tabular}{|c|c|c|c|c|c|c|c|c|c|c|c|c|c|c|c|c|c|c|c|c|c|c|c|c|}
\hline \multicolumn{10}{|c|}{ Professional Relationship + Interpersonal Relationship } & & \multicolumn{14}{|c|}{ Professional Relationship only } \\
\hline G7 & $\mathrm{A} 3$ & A4 & A6 & A7 & A8 & A11 & A12 & A13 & $\mathrm{A} 14$ & & G1 & G2 & G3 & G4 & G5 & G6 & G8 & G9 & A1 & A2 & A9 & A10 & A15 & \\
\hline $\mathrm{f}$ & $f^{*}$ & $\mathrm{f}^{*}$ & $\mathrm{f}$ & $\mathrm{m}$ & $\mathrm{f}$ & $\mathrm{f}$ & $\mathrm{m}$ & $\mathrm{f}^{*}$ & $\mathrm{~m}$ & & $\mathrm{f}$ & $\mathrm{f}$ & $\mathrm{m}$ & $\mathrm{m}$ & $\mathrm{m}$ & $\mathrm{m}$ & $\mathrm{m}$ & $\mathrm{f}$ & $\mathrm{m}^{*}$ & $\mathrm{f}^{*}$ & $\mathrm{~m}$ & $\mathrm{f}$ & $\mathrm{m}$ & \\
\hline \multicolumn{25}{|c|}{ Is it appropriate to display positive emotions and anger (as a frequent negative emotion) in HE teaching? $(\mathrm{x}=$ yes; $(\mathrm{x})=$ ambivalent; empty field $=$ no $)$} \\
\hline $\mathrm{x}$ & $x$ & $\mathrm{x}$ & n.a. & $\mathrm{x}$ & $x$ & $\mathrm{x}$ & $\mathrm{x}$ & $\mathrm{x}$ & $\mathrm{x}$ & & $\mathrm{x}$ & (x) & $\mathrm{x}$ & $\mathrm{x}$ & $x$ & $\mathrm{x}$ & (x) & (x) & (x) & $\mathrm{x}$ & $\mathrm{x}$ & $\mathrm{x}$ & $\mathrm{x}$ & Pos.E. \\
\hline $\mathrm{x}$ & & & & $\mathrm{x}$ & & & & $(\mathrm{x})$ & & & $\mathrm{x}$ & $x$ & $x$ & $x$ & $x$ & & $\mathrm{x}$ & $x$ & & $\mathrm{x}$ & $\mathrm{x}$ & $\mathrm{x}$ & & Anger \\
\hline \multicolumn{25}{|c|}{ Is it necessary to control the display of negative emotions? $(\mathrm{x}=$ yes; $(\mathrm{x})=$ ambivalent $)$} \\
\hline $\mathrm{x}$ & $\mathrm{x}$ & $\bar{x}$ & $\mathrm{x}$ & $\mathrm{x}$ & $\bar{x}$ & $\bar{x}$ & $\bar{x}$ & $\mathrm{x}$ & $\mathrm{x}$ & & $\mathrm{x}$ & $\mathrm{x}$ & $\mathrm{x}$ & $\mathrm{x}$ & $(\mathrm{x})$ & $\mathrm{x}$ & $\mathrm{x}$ & $\mathrm{x}$ & $\mathrm{x}$ & $\mathrm{x}$ & $\mathrm{x}$ & $\mathrm{x}$ & $\mathrm{x}$ & control \\
\hline \multicolumn{25}{|c|}{ The display of positive emotions: reactions $(\mathrm{x}=$ mentioned in the interview) } \\
\hline & & & & & & & & & & & $x$ & $x$ & & & $x$ & & $x$ & $\mathrm{x}$ & $x$ & & & & & POF \\
\hline $\mathrm{x}$ & & & & & $\mathrm{x}$ & & & & & & & & $\mathrm{x}$ & & & $x$ & & & & & & $x$ & & $\begin{array}{l}\text { PRA } \\
\end{array}$ \\
\hline $\mathbf{x}$ & $\mathbf{x}$ & $\overline{\mathbf{x}}$ & & & & & $\overline{\mathbf{x}}$ & & & 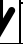 & & & & & & & & & & & & & & IER/H \\
\hline & & & & & & & & & & & & & & & & & & & & & & & & \\
\hline$x$ & & & & $x$ & $x$ & $x$ & & $x$ & $x$ & & & & & $x$ & & & & & & & & $\bar{x}$ & $x$ & ENT \\
\hline $\mathrm{x}$ & $\mathrm{x}$ & & & & & $\mathrm{x}$ & & $\mathrm{x}$ & & & & & & & & $\mathrm{x}$ & & & $\mathrm{x}$ & & $\mathrm{x}$ & & $\mathrm{x}$ & HUM \\
\hline
\end{tabular}

The display of negative emotions: reactions $(x=$ mentioned in the interview)

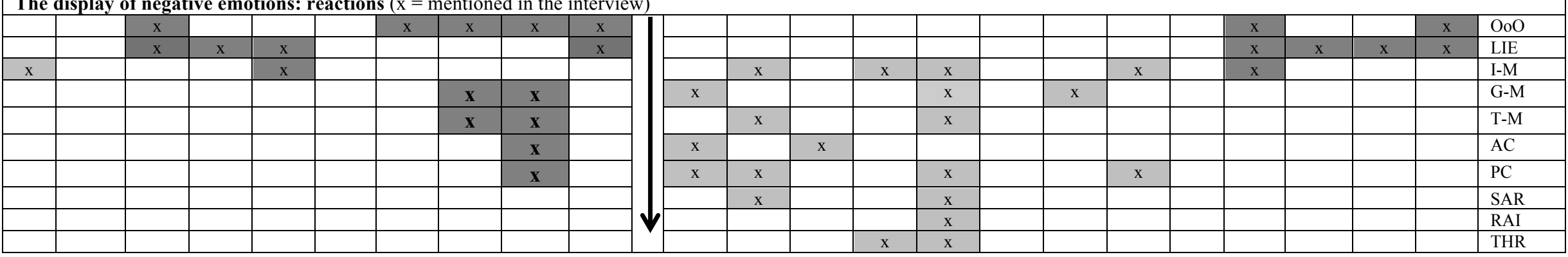

Note. Light shading = German teacher educators; Dark shading =Australian teacher educators; Pos.E. = Positive Emotions; POF = positive Feedback; PRA = praise; IER/H = intensive emotional reaction (verbally) + hugging students; ENT = enthusiasm; HUM = humour; OoO = one-on-one contact after the lesson; LIE = using less intensive emotion words; I-M = I-messages; $\mathrm{G}-\mathrm{M}=$ group messages; $\mathrm{T}-\mathrm{M}=$ transfer messages; $\mathrm{AC}=$ argumentative confrontation; $\mathrm{PC}=$ provocative argumentation; $\mathrm{SAR}=\mathrm{sarcasm} /$ irony; $\mathrm{RAI}=$ raising the voice; $\mathrm{THR}=$ threat, classroom relegation; n.a. = not applicable (no information on that aspect in the interview); *coming from another cultural background

A5 is not presented in the overview as she explicitly stated that she "does not take the emotional aspects" which made it impossible to code the main categories on emotion display. 


\subsection{Factors contributing to explain modes of emotion display and the quality of the teacher-} student relationship in German and Australian teacher educators: Intensive and deviant case analyses (Res Q 4)

Finally, it was of interest to explore the extent to which some central background variables of these teacher educators may contribute to explain the way they communicated their emotions in the classroom and their views of the quality of the TSR. This exploration was done through the close analysis of deviant and intensive cases.

In the German sample, the deviant case was G7, the teacher who reported strong interpersonal relationships with her students, whereas all other German teacher educators were allocated to the group "professional TSR only". Two German teachers (G2 and G5) who expressed rather extreme negative emotions in comparison to their colleagues were potential candidates for the intensive case for the German context. In order to control for possible gender effects, the female teacher (G2) was chosen for comparison. In the Australian sample the deviant case was A15, the teacher who expressed the most distant relationship to students and who emphasized "professionalism" the most, and the intensive case was A4, the teacher who showed the closest relationship to students and adopted the most intensive way of communicating her positive emotions. As background criteria the following aspects were used: position at university, age, experience in HE teaching, experience in school teaching, amount of out-of-class interactions, dedication for HE teaching (in teacher education) and having research duties beyond teaching duties.

The results of the comparisons are depicted in Figures 3 and 4. For both samples, the identification that a teacher reveals from teaching in HE - and in teacher education in particular - generated the most salient difference in how interactions with students were implemented (= dedication HE teaching). Both teachers who described an intense display of positive emotions and "close(r)" interpersonal relationships to students reported that they loved teaching and were very keen on teaching in teacher education, and enjoying the sharing of their own experiences as school teachers to student teachers. G7 could dedicate a lot of her time doing this, as she was a full-time lecturer; thus the position matched her interests as the following account illustrates:

That's a big part of my professional understanding, and afterwards I go out of these classes and I'm really ... feel like being on cloud nine. Then, I feel really good, then I know: Yeah, that's my job, that's what I wanna do. You know when I can inspire them for what they aspire to be. Wow, this really just warms my heart. So yes, that's, um, that's really my idealism that I bring into this job. You know, I really really like speaking about teaching, I like teaching a lot, but I also like to talk about school lessons, and I like to pique the students' interest.

\section{(I7, Germany)}

The dedication to teaching in teacher education was not as visible in the accounts of those two teachers who displayed more distant relationships and a less intense way of communicating positive emotions to their students. That might be traced back to several factors: this German teacher did not have a school teaching background herself and was quite inexperienced in HE teachings, which was accompanied by some problems in classroom management and thus feelings of insecurity. In the Australian sample, position at university might have contributed to differences. I15 had a background as a schoolteacher, but he was a sessional lecturer (= an external lecturer) who taught at university only once a week. He taught different courses on that day and thus, the amount of informal interactions he could have with students was limited. In addition, he expressed that he was not sure how long he would teach at university which suggested low(er) identification as a teacher educator at university. 


\begin{tabular}{|c|c|c|}
\hline \multicolumn{3}{|c|}{ German sample } \\
\hline 12 (female) & & 17 (female) \\
\hline PhD-Student & Position & Full-time lecturer \\
\hline$<30$ & Age & $>30$ \\
\hline$<5$ years & Experience & $>10$ years \\
\hline & Experience & \\
\hline No & $\begin{array}{l}\text { school } \\
\text { teaching }\end{array}$ & Yes \\
\hline Low & Out-of-class & Low \\
\hline Medium & $\begin{array}{l}\text { Dedication } \\
\mathrm{HE} \text { teaching }\end{array}$ & High \\
\hline Yes & Research & No \\
\hline $\begin{array}{l}\text { RS: Professional RS only } \\
\text { Display of positive emotions: low intensity } \\
\text { Display of negative emotions: high intensity }\end{array}$ & & $\begin{array}{l}\text { RS: Professional + Interpersonal RS } \\
\text { Display of positive emotions: high intensity } \\
\text { Display of negative emotions: low intensity }\end{array}$ \\
\hline
\end{tabular}

Figure 3: Case comparison: German sample

115 (male)

Figure 4. Case comparison: Australian sample 


\section{Discussion}

The present study explored the emotion display and the quality of the TSR at university from a teachers' perspective, with particular attention to cultural-educational differences between a sample of teachers from Australia and Germany. The findings revealed many similarities but also differences between the Australian and German teacher educators, in their emotion display and in the quality of the TSR. Bringing these two strands of findings together, and drawing on the literature on emotions in social relations (Boiger \& Mesquita, 2012; Parkinson et al., 2005), it can be concluded that not only cultural aspects but also the quality of the relationship formed between teachers and students within their respective cultural HE setting, is likely to impact on what is perceived by university teachers as appropriate ways of displaying emotions. Although a predominantly egalitarian TSR in the professional dimension prevailed in both groups, in which considering the instructor as facilitator supporting critical thinking and student centered learning processes (in contrast to a predominantly hierarchical TSR, which may be more common in the Chinese HE; see Zhang \& Zhang, 2013), the quality of the interpersonal dimension of the TSR appeared to differ between the two cultural-educational contexts.

Interpersonal relations between teachers and students were relatively pronounced in the Australian setting, while in the German sample the professional working relationship between students and teachers was emphasized, resulting in higher formality in student-teacher interactions. The importance given to caring in the interpersonal TSR by the Australian teacher educators might be partly explained in relation to the higher proportion of their students being from low SES in comparison to the German context. However, the formality versus informality in the interactions that also substantially contributed to the interpersonal TSR may be culturally informed and less dependent on student characteristics. Future studies will need to account for possible moderator variables, such as the students' background, when investigating teacher-student interactions and relationships. As argued by Safdar et al., (2009), relationship quality typically affects the way emotions are communicated, as the "closeness" of the interaction partner is regarded as a significant influencing factor of emotion display. Typically, people express emotions with higher intensity when relationships are close (Fischer \& Manstead, 2010). This was also evident in our study, but only for the positive emotions: Teacher educators, who formed more pronounced interpersonal relationships with their students, displayed their positive emotions more intensely, while they communicated the negative ones in a relatively reserved way. On the other hand, if teachers formed relationships mainly on a professional level, their positive emotions were communicated less intensely.

Although all teacher educators in this study believed in the necessity to control emotions in professional settings, the way emotion display was acted out in practice differed in the two culturaleducational contexts. While the majority of the Australian teachers communicated positive emotions immediately but avoided the direct and immediate display of anger, their German counterparts were less direct in the display of positive emotions but more immediate in the communication of anger. Furthermore, most of the German teacher educators did not perceive the controlled expression of anger as a threat for the professional TSR but instead regarded it as a necessary component of their function as a teacher. Some German teacher educators explicitly stated that it is not about "liking them", but about learning as much as possible from their courses. These views are consistent with Yuu (2010), who argued that expression of negative emotions in an appropriate way does not risk relationships but bridges "the psychological and emotional distance between teachers and students" (p. 76). In contrast, some Australian teacher educators stressed their effort not to display strong negative emotions in order to maintain positive relationships with students and not to risk authority. In a recent study, Bartram (2015) found that sometimes students take advantage of close and caring relationships with HE teachers, a behavior he coined "affective strategizing" (p. 68). This suggests that a caring attitude of HE teachers may not necessarily be positive, as it comes with individual costs for the teacher (e.g. a higher workload) and with students capitalizing on this attitude (for a conceptualization on the caring HE teacher, see Walker \& Gleaves, 2016).

Interestingly, the less pronounced acceptance of anger expression in the Australian sample appears consistent with countries that score higher on Hofstede and Hofstede's (2005) collectivistic dimension, 


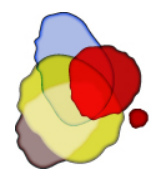

whereas the display of negative emotions is regarded as the right of the individual in more individualistic countries. However, the conclusion that Australian HE teacher educators might display more collectivistic tendencies than their German counterparts cannot be made based on the present data. In fact, Australia scores higher on Hofstede and Hofstede's individualism index than Germany. In order to clarify that to some degree unexpected finding, future research will need to explore the extent to which different degrees of individualistic and collectivistic tendencies can be found within so-called "individualistic or collectivist" cultures / countries and how these differences are connected to teacher motivation, emotion and behaviour. We would argue that "individualism-index" dimensions are not sensitive enough to interpret differences in interactions and relationships, and that the educational context and the norms, values and rules within this context provide more promising explanatory elements. The combination of cultural and contextual elements was captured in the term "cultural-educational context" (Volet, 2001) that we have used throughout the article.

Apart from differences emerging between the accounts of the Australian and German teacher educators, it is important to also note their shared beliefs. For example, beliefs regarding the necessity to control the display of negative emotions by simultaneously maintaining a relatively high degree of authenticity (an explicit goal in individualistic countries, Safdar et al., 2009), were shared by Australian and German teacher educators alike, which supports previous findings. For example, Mendzheritskaya and Hansen (2013) (see also Mendzheritskaya, Hansen \& Horz, 2015) found that German and Russian HE lecturers showed a greater authenticity in displaying positive emotions, which was also the case in the present sample, while negative emotions were displayed with lower expressivity based on the belief that negative emotions must be controlled in a professional setting. Another aspect shared by many teachers in both countries, in particular in Australia, was the importance of displaying enthusiasm for the teaching subject in class. This is reminiscent of what Neumann (2006) referred to as "passionate thought" inspired by scholarly work in the respective subject area, and which should, according to Neumann, be transferred to students through an enthusiastic teaching practice in order to cultivate their motivation for the subject.

Finally, a high variety of emotion display modes within each cultural-educational context were detected, which could be traced back to different factors on the individual level, such as personality (Matsumoto, 2006). This supports the findings resulting from a meta-analysis done by Van Hemert, Poortinga, and van de Vijver (2007) who have found several moderators that reduced the cross-cultural variance in emotion variables. A particular relevant factor influencing the display mode of emotions and the quality of the TSR seems to be the dedication for teaching in general and teaching in teacher education specifically. As the comparative case-analysis has shown, teachers who identified strongly with the teaching profession, reported closer relationships with their students and also expressed more intensive positive emotions. Furthermore, position at university and prior teaching experience (in HE and at school) also appeared to contribute to the quality of the TSR and the display of emotions.

\section{Conclusion: Study limitations and implications}

The results of the present study have significant implications particularly for research in the internationalization of HE. While there is extensive literature on the experiences of international students in HE, these experiences are under-explored for HE faculty (Bedenlier \& Zawacki-Richter, 2015; Shimmi, 2014). Our interview accounts have revealed different modes of forming relationships with students and displaying emotions in teaching, depending on the cultural-educational context. There was also evidence that new teachers from a cultural background different from the local context can feel insecure about how to behave in an unfamiliar classroom environment. As reported in Volet and Jones' (2012) review of literature, scholars teaching in another country may need support to adapt to new and culturally different teaching environments. Many strategies may support their adaptation. For example, in their first semester, an 
international and a national scholar could conduct joint courses, which would allow the scholars to share how students and teachers typically interact in the respective countries. In doing so, the international scholar could develop a sense of the "academic habitus" that prevails in the host country. Reflection groups that consist of international teachers and at least one national teacher meeting regularly to exchange and discuss experiences may be useful. Darwin and Palmer (2009) introduced the idea of "mentoring circles", which they present as a form of group mentoring aimed at staff development in a HE context. Mentoring circles could be appropriate environments to assist international scholars to adapt to their new work environment. More generally, Luna and Cullen (1995) describe mentoring as a key principle in empowering faculty, with special strategies for mentoring minority faculty (e.g., scholars with a different cultural background).

Helping new academics from a different cultural-educational background to adapt to local teaching practices is important but it is particularly critical in the field of teacher education. This is because teacher educators do not only teach but are also expected to model teaching behaviour to prospective teachers. Therefore they should be aware, not only of appropriate teaching practices in the HE field, but also of those expected in the school context. For example, they should become familiar about the feedback practices in the new country (how is it expected to communicate satisfaction with a students' achievement, whether in an emotionally intense way or in a more reserved way?), and about the degree of informality or formality in teacher-student interactions at school. Furthermore, as bridging educational theory with educational practice (Garcia-Aracil, 2012) is an important contributing factor to study satisfaction, teacher educators coming from another cultural-educational background should gain in-depth understanding of the educational practices of the new country. More generally, fostering socio-emotional competence (Jennings \& Greenberg, 2009 ) in teacher educators, for example by analyzing classroom instructional and interaction practices through videos (for schoolteachers, see i.e. Seidel et al., 2011), appears an important avenue in the professionalizing of teacher educators.

The finding of differences in the perceived-as-appropriate display rules of emotions in educational settings, as well as the quality of the TSR, suggests that teaching strategies cannot be considered as techniques that can simply be transferred to different cultural-educational settings. International educators need to become aware of the frequently unexpressed and implicit cultural specifics of teaching in HE classrooms. Awareness of cultural specifics of their own familiar educational environments as well as those of the new environment, would not only promote teaching quality from the outset but also teachers' and students' satisfaction in the teaching learning process. Diener and Diswas-Diener's (2008) research has found that satisfaction with relationships is the most important predictor for life-satisfaction. Developing competence in a range of cultural appropriate display rules can, thus, be regarded as an important factor for maintaining teachers' wellbeing (Woods, 2010) in international education settings at home or abroad (for a critical discussion on the increased emphasis on emotions and emotional well-being in education, see for example Ecclestone \& Hayes, 2009; Ecclestone, 2012).

Many directions for future research emerge from the present study. Methodologically, there is a need for more situated approaches to explore teacher emotions in the classroom. For example, systematic (video-) observations in concrete teaching situations, combined with subsequent stimulated recall interviews, would generate rich insights on the cultural-specifics of teacher-student interactions across countries, as well as culturally diverse classroom settings. Video-observations could be used together with teacher questionnaires (e.g. using the "Display Rule Assessment Inventory" adapted to the HE context; see Mendzheritskaya and Hansen 2013), following a mixed-methods approach (Creswell \& Plano-Clark, 2011). The present study relied on self-reports of teachers, which may have drawn some responses that were affected by social desirability bias to some extent. Furthermore our study addressed emotions and relationships directly. Other research - for example the study by Postareff and Lindblom-Ylänne (2011) - did not explore directly HE teachers' emotions, but issues related to emotions nevertheless emerged from the answers given to other interview questions. Both ways of exploring emotions are possible avenues in emotion research and the appropriateness of the chosen approach depends on the research aim and the sample (e.g in terms of their willingness and ability to reflect educational practices including the own emotional and mental processes). Future studies should combine such subjective measures with more objective measures, regardless of 
whether emotions are assessed through direct or indirect questioning in the subjective-coined part of the study.

It also seems necessary to develop quantitative measure that would make it possible to assess the multidimensionality of the quality of the TSR in HE (Hagenauer \& Volet, 2014c). This could involve the development of coding schemes to record systematic observations of teacher-student interactions; coding schemes that would allow inferences to be drawn on the quality of the TSR. Furthermore, correlational studies should follow as well as longitudinal studies exploring how display modes might affect the establishment of relationships and vice versa.

In terms of limitations, the present study was conducted with teacher educators, which suggests caution in generalizing to university teachers in other domains. As argued by Alheit (2009), teaching practices vary across domains, departments, and institutions due to differences in the academic habitus. The impact of moderating variables should therefore be examined systematically in future studies, for example, the teaching domain (e.g. soft versus hard sciences), teachers' role and status in the university (professor, lecturer, PhD-student with teaching duties, casual) (Richardson \& Radloff, 2014), the amount and quality of prior teaching experience (Meanwell \& Kleiner, 2014), and the value placed on teaching at the respective university. The latter might also influence teachers' identification as a teacher and his/her motivation for teaching, which might in turn impact on the emotional labour required in teaching (Visser-Wijnveen, Stes, \& Van Petegem, 2014). By taking these factors into account, variability in emotion display and the relationship quality in different cultural-educational contexts could be better understood. On an interpersonal level, gender, personality (e.g., the Big Five or people's idiocentric vs. allocentric tendencies) as well as ethnicity and cultural background should be accounted for. In terms of cultural background, DeCuir-Gunby and Williams-Johnson (2014) discussed people's difficulties to read the expression of emotions of culturally distant others. This is an important issue if international students are taught in HE classrooms or if teachers teach in a foreign or ethnically unfamiliar context. In addition, by applying an autobiographical approach it would be possible to explore how the past experiences or the "personal history", as coined by Day and Leitch (2001), could contribute to our understanding of emotion display and TSR-building processes in HE settings.

Finally, some cultures may be more heterogeneous than others. In our study, the Australian sample comprised a few immigrants, while the German teacher educators were all local. Furthermore, it is well known that equating country with culture is problematic (e.g. Matsumoto et al., 1998; Volet \& Jones, 2012), therefore there should be caution in the interpretation of the findings, keeping in mind that educational practices are constantly changing in increasingly global environments, and most importantly also reflect individual preferences. Concluding, as observed by Van Hemert et al. (2007), studies on cultural issues in HE teaching should go beyond frequently made comparisons between individualistic and collectivistic cultures or countries. This study revealed a high variation of cultural-educational practices within two socalled "individualistic" countries (Hofstede \& Hofstede, 2005). This calls for a reconceptualization of crosscultural research on the relationship between emotion display and the TSR in HE teaching contexts.

\section{Keypoints}

- Insight into university teachers' perceptions of the characteristics of quality TSR and appropriate emotion display is essential in the context of the fast developing internationalization of higher education.

- This study revealed major qualitative differences in the display of positive and negative emotions in two distinct cultural-educational contexts.

- The study also unveiled differences across cultural-educational contexts in the importance given by teachers to keeping professional and formal working relationship with students or alternatively showing informality and caring in the interpersonal TSR. 
International scholars and teachers, like mobility students, need support to adapt to unfamiliar cultural-educational environments.

\section{References}

Alheit, P. (2009). Die symbolische Macht des Wissens. Exklusionsmechanismen des universitären Habitus [The Symbolic Power of Knowledge. Mechanism of Exclusion of the Academic Habitus]. Presentation held at the University of Heidelberg (3.6.2009).

Altbach, P. G., \& Knight, J. (2007). The internationalization of higher education: Motivations and realities. Journal of Studies in International Education, 11 (3), 290-305. doi: 10.1177/1028315307303542

Barber, L. K., Grawitch, M. J., Carson, R. L., \& Tsouloupas, C. N. (2010.) Costs and benefits of supportive versus disciplinary emotion regulation strategies in teachers. Stress and Health, 27, e173-e187. doi: 10.1002/smi.1357.

Bartram, B. (2015). Emotion as a student resource in higher education. British Journal of Educational Studies, 63 (1), 67-84. doi: 0.1080/00071005.2014.980222

Baumeister, R. F., \& Leary, M. R. (1995). The need to belong: Desire for interpersonal attachments as a fundamental human motivation. Psychological Bulletin, 117, 497-529. doi: 10.1037/00332909.117.3.497

Beard, C., Clegg, S., \& Smith, K. (2007). Acknowledging the affective in higher education. British Educational Research Journal, 33 (2), 235-252. doi: 10.1080/01411920701208415

Bedenlier, S., \& Zawacki-Richter, O. (2015). Internationalization of higher education and the impacts on academic faculty members. Research in Comparative and International Education, 10 (2), 185-201. Online first: doi: 10.1177/1745499915571707

Boiger, M., \& Mesquita, B. (2012). The construction of emotion in interactions, relationships, and cultures. Emotion Review, 4 (3), 221-229. doi: 10.1177/1754073912439765

Brennan, R. L., \& Prediger, D. J. (1981). Coefficient Kappa: Some uses, misuses, and alternatives. Educational and Psychological Measurement, 41, 687-699. doi: 10.1177/001316448104100307

Bortz, J., \& Döring, N. (2006). Forschungs- und Untersuchungsplanung. Heidelberg: Springer.

Chen, Y.-H., \& Kristjansson, K. (2011). Private feelings, public expression: Professional jealousy and the moral practice of teaching. Journal of Moral Education, 40 (3), 349-358. doi: $10.1080 / 03057240.2011 .596336$

Cranton, P., \& Carusetta, E. (2004). Perspectives on authenticity in teaching. Adult Education Quarterly, 55 (5), 5-22. doi: 10.1177/0741713604268894

Creswell, J. W., \& Plano Clark, V. L. (2011). Designing and conducting mixed methods research (2 ${ }^{\text {nd }}$ ed.). Los Angeles: Sage.

Darwin, A., \& Palmer, E. (2009). Mentoring circles in higher education. Higher Education Research \& Development, 28 (2), 125-136. doi: 10.1080/07294360902725017

Day, C., \& Leitch, R. (2001). Teachers' and teacher educators' lives: The role of emotion. Teaching and Teacher Education, 17, 403-415. doi: 10.1016/S0742-051X(01)00003-8

DeCuir-Gunby, J., \& Williams-Johnson, M. R. (2014). The influence of culture on emotions. Implications for education. In R. Pekrun, \& L. Linnenbrink-Garcia (Eds.), International handbook of emotions in education (pp. 539-557). New York: Routledge.

Deci, E. L., \& Ryan, R. M. (Eds.). (2002). Handbook of self-determination research. Rochester: University of Rochester Press.

Diener, E., \& Biswas-Diener, R. (2008). Happiness: Unlocking the mysteries of psychological wealth. Malden, MA: Blackwell Publishing.

Ecclestone, K. (2012). From emotional to psychological well-being to character education: Challenging policy discourses of behavioural science and "vulnerability". Research Papers in Education, 27 (4), 463-480. doi: 10.1080/02671522.2012.690241 
Ecclestone, K., \& Hayes, D. (2009). Changing the subject: the educational implications of developing emotional well-being. Oxford Review of Education, 35 (3), 371-389. doi: 10.1080/03054980902934662

Eid, M., \& Diener, E. (2001). Norms for experiencing emotions in different cultures: Inter-and intranational differences. Journal of Personality and Social Psychology, 81 (5), 869-885. doi: 10.1037//00223514.81.5.869

Ellsworth, P. C., \& Scherer, K. R. (2003). Appraisal processes in emotion. In R. J. Davidson, K. R. Scherer, \& H. Hill Goldsmith (Eds.), Handbook of affective sciences (pp. 572-595). Oxford: University Press.

Fischer, A. H., \& Manstead, A. S. R. (2010). Social functions of emotions. In M. Lewis, J. M. HavilandJones, \& L. Feldman Barrett (Eds.), Handbook of Emotions ( $3^{\text {rd }}$ ed.) (pp. 456-468). New York: Guilford Press.

Fischer, A. H., Manstead, A. S. R., Evers, C., Timmers, M., \& Valk, G. (2004). Motives and norms underlying emotion regulation. In P. Phillippot \& R. S. Feldman (Eds.), The regulation of emotion (pp. 187-210). Mahwah, NJ: Lawrence Erlbaum.

Frenzel, A. (2014). Teacher emotions. In R. Pekrun, \& L. Linnenbrink-Garcia (Eds.), International handbook of emotions in education (pp. 494-519). New York: Routledge.

Frenzel, A. C., Goetz, T., Luedtke, O., Pekrun, R., \& Sutton, R. (2009). Emotional transmission in the classroom: Exploring the relationship between teacher and student enjoyment. Journal of Educational Psychology, 101, 705-716. doi: 10.1037/a0014695

Garcia-Aracil, A. (2012). A comparative analysis of study satisfaction among young European higher education graduates. Irish Educational Studies, 31, 223-243. doi: 10.1080/03323315.2012.660605

Garner, P. W. (2010). Emotional competence and its influences on teaching and learning. Educational Psychology Review, 22, 297-321. doi: 0.1007/s10648-010-9129-4

Gates, G. S. (2000). The socialization of feelings in undergraduate education: A study of emotional management. College Student Journal, 34 (4), 485-504.

Gläser-Zikuda, M. \& Mayring, Ph. (2003). A qualitative approach to learning emotions at school. In Ph. Mayring, \& Ch. v. Rhöneck (Eds.), Learning Emotions. The influence of affective factors on classroom learning (pp. 103-126). Berlin: Peter Lang.

Gross, J. J. (2010). Emotion regulation. In M. Lewis, J. M. Haviland-Jones, \& L. Feldman Barrett (Eds.), Handbook of Emotions ( $3^{\text {rd }}$ ed.) (pp. 497-512). New York: Guilford Press.

Gross, J. J. (2002). Emotion regulation: Affective, cognitive, and social consequences. Psychophysiology, 39 (3), 281-291. doi: 10.1017.S0048577201393198

Hagenauer, G., Hascher, T., \& Volet, S. E. (2015). Teacher emotions in the classroom: associations with students' engagement, discipline in the classroom and the interpersonal teacher-student relationship. European Journal of Psychology of Education, 30 (4), 385-403. doi: 10.1007/s10212-015-0250-0

Hagenauer, G., \& Volet, S. E. (2014a). "I don't think I could, you know, just teach without any emotion": Exploring the nature and origin of university teachers' emotions. Research Papers in Education, 29 (2), 240-262. doi: 10.1080/02671522.2012.754929

Hagenauer, G., \& Volet, S. E. (2014b). "I don't hide my feelings, even though I try to": Insight into teacher educator emotion display. Australian Educational Researcher, 41 (3), 261-281. doi: 10.1007/s13384013-0129-5

Hagenauer, G., \& Volet, S. E. (2014c). Student-teacher relationship at university: An important yet underresearched field. Oxford Review of Education, 40 (3), 370-388. doi: 10.1080/03054985.2014.921613

Hascher, T., \& Hagenauer, G. (2016). Openness to theory and its importance for pre-service teachers' selfefficacy, emotions, and classroom behaviour in the teaching practicum. International Journal of Educational Research, 77, 15-25. doi: 10.1016/j.ijer.2016.02.003

Hastings, W. (2008). I felt so guilty: emotions and subjectivity in school-based teacher education. Teachers and Teaching: Theory and Practice, 14 (5-6), 497-513. doi: 10.1080/13540600802583655

Hatfield, E., Bensman, L., Thornton, P. D., \& Rapson, R. L. (2014). New perspectives on emotional contagion: a review of classic and recent research on facial mimicry and contagion. Interpersona, 8 (2), 159-179. doi:10.5964/ijpr.v8i2.162 
Hochschild, A. R. (1983). The managed heart: Commercialization of human feelings. Berkeley: University of California Press.

Hofstede, G., \& Hofstede, G. J. (2005). Cultures and organization: Software of the mind. London: McGrawHill.

Isenbarger, L., \& Zembylas, M. (2006). The emotional labour of caring in teaching. Teaching and Teacher Education, 22, 120-134. doi: 10.1016/j.tate.2005.07.002

Jennings, P. A., \& Greenberg, M. T. (2009). The prosocial classroom: Teacher social and emotional competence in relation to student and classroom outcomes. Review of Educational Research, 79, 491-525. doi: 10.3102/0034654308325693

König, J., \& Blömeke, S. (2013). Germany. In J. Schwille, L. Ingvarson, \& Holdgreve-Resendez (Eds.), TEDS-M Encyclopedia. A guide to teacher education context, structure, and quality assurance in 17 countries. Retrieved from http://www.iea.nl/fileadmin/user_upload/Publications/Electronic_versions/TEDS-M_Encyclopedia.pdf

Koopman-Holm, B., \& Matsumoto, D. (2011). Values and display rules for specific emotions. Journal of Cross-Cultural Psychology, 42, 355-371. doi: 10.1177/0022022110362753

Lazarus, R. S. (1999). Stress and emotion. A new synthesis. London: Free Association Books.

Luna, G., \& Cullen, D. L. (1995). Empowering the faculty. Mentoring redirected and renewed. ASHE-ERIC Higher Education Report No. 3. Washington, D. C.: The George Washington University, Graduate School of Education and Human Development.

Lunenberg, M., Korthagen, F., \& Swennen, A. (2007). The teacher educator as role model. Teaching and Teacher Education, 23, 586-601. doi: 10.1016/j.tate.2006.11.001

Markus, H. R., \& Kitayama, S. (1991). Culture and the self: Implications for cognition, emotion, and motivation. Psychological Review, 98, 224-233. doi: 10.1037/0033295X98.2.224

Matsumoto, D. (2006). Are cultural differences in emotion regulation mediated by personality traits? Journal of Cross-Cultural Psychology, 37, 421-437. doi: 10.1177/0022022106288478

Matsumoto, D., Takeuchi, S., Andayani, S., Kouznetsova, N., \& Krupp. D. (1998). The contribution of individualism vs. collectivism to cross-national differences in display rules. Asian Journal of Social Psychology, 1, 147-165. doi: 10.1111/1467-839X.00010

Mayring, P. (2000). Qualitative content analysis. Forum Qualitative Social Research, 1 (2). Retrieved from http://www.qualitative-research.net/index.php/fqs/article/view/1089/2385

Meanwell, E., \& Kleiner, S. (2014). The emotional experience of first-time teaching: Reflections from graduate instructors, 1997-2006. Teaching Sociology, 42 (1), 17-27. doi: 10.1177/0092055X13508377

Mendzheritskaya, J., \& Hansen, M. (2013, August). Shall I show my anger? Display rules in lecturer-student interaction in Germany and Russia. Paper presented at the 15th Biennal EARLI conference. Munich, Germany.

Mendzheritskaya, J., Hansen, M., \& Horz, H. (2015). Emotional display rules at universities in Russia and Germany. Russian Psychological Journal, 12 (4).

Mesquita, B. (2007). Emotions are culturally situated. Social Science Information, 46, 410-415. doi: $10.1177 / 05390184070460030107$

Moore, S., \& Kuol, N. (2007). Matters of the heart: Exploring the emotional dimensions of educational experience in recollected accounts of excellent teaching. International Journal of Academic Development, 12 (2), 87-98. doi: 10.1080/13601440701604872

Moran, C. M., Diefendorff, J. M., \& Greguras, G. J. (2013). Understanding emotional display rules at work and outside of work: The effects of country and gender. Motivation and Emotion, 37, 323-334. doi: 10.1007/s11031-012-9301-x

Neumann, A. (2006). Professing passion: emotion in scholarship of professors at research universities. American Educational Research Journal, 43 (3), 381-424. Retrieved from http://www.jstor.org/stable/4121764

Newberry, M., Gallant, A., \& Riley, P. (Eds.). (2013). Emotion and school: Understanding how the hidden curriculum influences relationships, leadership, teaching, and learning. UK: Emerald.

Nias, J. (1989). Primary teacher talking. A study of teaching as work. London: Routledge. 
Oplatka, I. (2007). Managing emotions in teaching: Towards an understanding of emotion displays and caring as nonprescribed role elements. Teachers College Record, 109 (6), 1374-1400.

Parkinson, B., Fischer, A. H., \& Manstead, A. S. R. (2005). Emotion in social relations. New York: Psychology Press.

Pekrun, R. (2006). The control-value theory of achievement emotions: assumptions, corollaries, and implications for educational research and practice. Educational Psychology Review, 18, 315-341. doi: 10.1007/s10648-006-9029-9

Pillen, M., Beijaard, D., \& den Brok, P. (2013). Professional identity tensions of beginning teachers. Teachers and Teaching: Theory and Practice, 19 (6), 660-678. doi: 10.1080/13540602.2013.827455

Postareff, L., \& Lindblom-Ylänne, S. (2011). Emotions and confidence within teaching in higher education. Studies in Higher Education, 36, 799-813. doi: 10.1080/03075079.2010.483279

Quinlan, K. M. (2016). How emotions matters in four key relationships in teaching and learning in higher education. College Teaching. Online first: doi: 10.1080/87567555.2015.1088818

Ria, L., Sève, C., Saury, J., Theureau, J., \& Durand, M. (2003). Beginning teachers' situated emotions: A study of first classroom experiences. Journal of Education for Teaching, 29 (3), 219-233. doi: $10.1080 / 0260747032000120114$

Richardson, S., \& Radloff. A. (2014). Allies in learning: Critical insights into the importance of staff-student interactions in university education. Teaching in Higher Education, 19 (6), 603-615. doi: 10.1080/13562517.2014.901960

Safdar, S., Friedlmeier, W., Matsumoto, D., Yoo, S. H., Kwantes, C., Kakai, H., \& Shigemasu, E. (2009). Variations in emotional display rules within and across cultures: A comparison between Canada, USA, and Japan. Canadian Journal of Behavioural Science, 41 (1), 1-10. doi: 10.1037/a0014387

Schutz, P. A. (2014). Inquiry on teachers' emotion. Educational Psychologist, 49, 1-12. doi: $10.1080 / 00461520.2013 .864955$

Schutz, P. A., \& Zembylas, M. (Eds.). (2011). Advances in teacher emotion research. The impact on teachers' lives. Heidelberg: Springer.

Schwarz, S. H., \& Ros, M. (1995). Values in the west: A theoretical and empirical challenge to the individualism-collectivism cultural dimension. World Psychology, 1, 99-122.

Seidel, T., Stürmer, K., Blomberg, G., Kobarg, M., \& Schwindt, K. (2011). Teacher learning from analysis of videotaped classroom situations: Does it make a difference whether teachers observe their own teaching or that or others? Teaching and Teacher Education, 27, 259-267. doi: 10.106/j.tate.2010.08.009

Shimmi, Y. (2014). Experiences of japanese visiting scholars in the united states: An exploration of transition. $\mathrm{PhD}$, Boston College, 2014. Retrieved from http://hdl.handle.net/2345/3783

Sutton, R. E., \& Wheatley, K. F. (2003). Teachers' emotions and teaching: a review of the literature and directions for future research. Educational Psychology Review, 15, 327-358. doi: 10.1023/A:1026131715856

Titsworth, S., McKenna, T. P., Mazer, J. P., \& Quinlan, M. M. (2013). The bright side of emotion in the classroom: Do teachers' behaviors predict students' enjoyment, hope, and pride? Communication Education, 62 (2), 191-209. doi: 10.1080/03634523.2013.763997

Timostsuk, I., \& Ugaste, A. (2012). The role of emotions in student teachers' professional identity. European Journal of Teacher Education, 35 (4), 421-433. doi: 10.1080/02619768.2012.662637

Trigwell, K. (2012). Relations between teachers' emotions in teaching and their approaches to teaching in higher education. Instructional Science, 40, 607-621. doi: 10.1007/s1125-011-9192-3

Tsai, J. L., Knutson, B., \& Fung, H. H. (2006). Cultural variation in affect valuation. Journal of Personality and Social Psychology, 90, 288-307. doi: 10.1037/0022-3514.90.2.288

Van Hemert, D. A., Poortinga, Y. H., \& van de Vijver, F. J. R. (2007). Emotion and culture: A Metaanalysis. Cognition and Emotion, 21 (5), 913-943. doi: 10.1080/02699930701339293

Visser-Wijnveen, G. J., Stes, A., \& Van Petegem, P. (2014). Clustering teachers' motivations for teaching. Teaching in Higher Education, 19 (6), 644-656. doi: 10.1080/13562517.2014.901953 
Volet, S. (2001). Understanding learning and motivation in context: A multi-dimensional and multi-level cognitive-situative perspective. In S. Järvelä, \& S. Volet (Eds.)., Motivation in learning contexts: Theoretical advances and methodological implications (pp. 57-82). Elmsford, NY: Pergamon.

Volet, S. E., \& Jones, C. (2012). Cultural transitions in higher education: Individual adaptation, transformation and engagement. In S. Karabenick, \& T. Urdan (Eds.), Advances in achievement and motivation series (Vol. 17): Transitions across schools and cultures (pp. 241-284). Bingley, UK: Emerald.

Walker, C., \& Gleaves, A. (2016). Constructing the caring higher education teacher: A theoretical framework. Teaching and Teacher Education, 54, 65-76. doi: 10.1016/j.tate.2015.11.013

Woods, C. (2010). Employee Wellbeing in the higher education workplace: A role for emotion scholarship. Higher Education, 60, 171-185. doi: 10.1007/s10734-009-9293-y

Yuu, K. (2010). Expressing emotions in teaching: Inducement, suppression, and disclosure as caring profession. Educational Studies in Japan. International Yearbook, 5, 63-75.

Zhang, Q., \& Zhang, J. (2013). Instructors' positive emotions: Effects on student engagement and critical thinking in U.S. and Chinese classrooms. Communication Education, 62 (4). 395-411. doi: $10.1080 / 03634523.2013 .828842$

Zhang, Q., \& Zhu, W. (2008). Exploring emotion in teaching: Emotional labor, burnout, and satisfaction in Chinese higher education. Communication Education, 57 (1), 105-133. doi: $10.1080 / 03634520701586310$ 